\title{
Help-seeking for Suicidal Thoughts in the Poisoned Patients at Loghman Hakim Teaching Hospital in Tehran, Iran
}

\author{
Mehrnoosh Inanlou ${ }^{1}$, Shaghayegh Basiri ${ }^{2}$, Nasim Zamani $^{3}$, Hamid Haghani ${ }^{4}$
}

\begin{abstract}
Background \& Aims: A history of suicide attempt is the most important risk factor for repeated and successful suicide. Seeking help is essential to access to proper mental healthcare services, and appropriate help-seeking could protect individuals against the risks of suicidal thoughts and behavioral progress in this regard. In addition, seeking help from a professional or personal source that could facilitate access to professional psychological help mitigates or eliminates the immediate risk of successful suicide in those with suicidal thoughts or manifesting suicidal behaviors. The level of help-seeking is higher in the areas where the suicide rate is lower. Considering the role of cultural background in help-seeking, studies must be conducted in Iran to gain insight into the intention of help-seeking for suicidal thoughts. The present study aimed to determine the intention of help-seeking from formal sources for suicidal thoughts and assess its correlation demographic factors in the poisoned patients with a history of suicide attempt prior to the current condition in Loghman Hakim teaching hospital in Tehran, Iran.

Materials \&Methods: This cross-sectional, descriptive study was conducted on all the poisoned patients with a history of suicide attempt prior to the current condition, who were being discharged from the men's and women's poison wards of Loghman Hakim teaching hospital affiliated to Shahid Beheshti University of Medical Sciences in Tehran, Iran. In total, 130 patients were selected via continuous sampling from late April to late June, 2019. In addition to the demographic form (age, gender, education level, marital status, occupation status, economic status, number of suicide attempts, family history of suicide, history of receiving consultative and psychological services, history of psychiatric medication use under the supervision of a physician, and history of admission to the psychological ward), data were collected using the general help-seeking questionnaire (GHSQ) developed by Wilson et al. (2005) in Australia for the measurement of help-seeking intentions. To confirm the validity of the GHSQ, the process of translation and re-translation was utilized. Moreover, the reliability of the scale was confirmed by 15 eligible poisoned patients (not the main research units) who completed the questionnaire, and the Cronbach's alpha coefficient was calculated to be 0.70 . After obtaining informed consent and explaining the responding process of the questionnaires, the demographic form and GHSQ were completed for each research unit by the researcher based on the responses of the patients within 15-20 minutes at their bedside. Data were obtained from 130 completed questionnaires. Data analysis was performed in SPSS version 20, and descriptive statistics were used in the form of tables and numerical measures in order to describe the research units. To determine the correlations between the demographic variables and help-seeking intentions, the data were analyzed using Pearson's correlation-coefficient, independent t-test, and the analysis of variance (ANOVA) at the significance level of $\mathrm{P}<0.05$.
\end{abstract}

Results: In total, $76.9 \%$ of the participants were female, and the age of the patients was within the range of 18-57 years (mean: $26.76 \pm 9.1$ years). Among the patients, $40.0 \%$ had a high school diploma, $56.9 \%$ were single, $61.5 \%$ were unemployed, and $41.5 \%$ had an average economic status. The number of suicide attempts was 2-14 times (mean: $2.91 \pm 2.3$ ), and $11.5 \%$ of the subjects had a family history of suicide attempt. In addition, $41.5 \%$ had no history of receiving consultative and psychological services, $52.3 \%$ had no history of psychiatric medication use under the supervision of a physician, and $20.8 \%$ had a history of admission to the psychiatric ward. The helpseeking intentions for suicidal thoughts from formal sources were low, with the mean of $2.51 \pm 1.18$ (achievable

\footnotetext{
1. Instructor, Department of Pediatric and Psychiatric Nursing, School of Nursing and Midwifery, Iran University of Medical Sciences, Tehran, Iran

2. MS in Psychiatric Nursing, School of Nursing and Midwifery, Iran University of Medical Sciences, Tehran, Iran

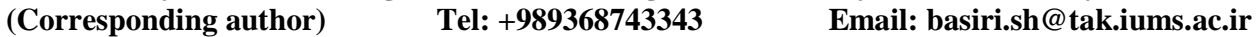

3. Assistant Professor, Department of Clinical Toxicology, School of Medicine, Loghman Hakim Hospital, Shahid Beheshti University of Medical Sciences, Tehran, Iran

4. Instructor, Department of Biostatistics, School of Health, Iran University of Medical Sciences, Tehran, Iran
} 
range: 1-7), and the most significant formal sources of help-seeking intentions were psychologists (3.78 \pm 2.65$)$, psychiatrists (3.64 \pm 2.58$)$, and social services hotlines (2.34 \pm 2.08$)$, respectively. Among the demographic variables, no significant correlations were observed between help-seeking intentions from formal sources and age, gender, education level, marital status, occupation status, economic status, number of suicide attempts, history of receiving consultative and psychological services, history of psychiatric medication use under the supervision of a physician, and history of admission to the psychiatric ward. History of suicide attempt in the first-degree family members was the only demographic variable that had a significant correlation with help-seeking intentions from formal sources $(\mathrm{P}=0.021)$, and the mean score of help-seeking intentions from formal sources was higher in the patients with a family history of suicide attempt.

Conclusion: According to the results, the help-seeking intentions from formal sources for suicidal thoughts were low in the poisoned patients with a history of suicide attempt. Help-seeking is an effective coping strategy when experiencing suicidal thoughts, which facilitates access to professional psychological help and plays a key role in reducing the rate of suicide; therefore, efforts should be made to promote help-seeking. The individuals who are at the risk of suicide need interventions developed to improve mental health care, especially primary care to encourage quicker help-seeking from proper sources. In this regard, measures such as the normalizing of helpseeking from formal sources, expanding insurance coverage to cover mental healthcare services, and improving communication skills in the families of those with a history of suicide could act as the facilitators of help-seeking from formal sources, as well as the training, identification, and referral of these individuals to available professionals, such as teachers and clerics. The familiarity of these individuals with various help-seeking sources (e.g., social aid hotlines and media campaigns) to increase the level of help-seeking may also facilitate the access of individuals to proper help-seeking sources. Moreover, the barriers against help-seeking in the individuals attempting suicide must be identified and mitigated. In this study, only about half of the individuals with a history of suicide attempt had a history of visiting a professional psychologist or using psychiatric medications under the supervision of a physician, while their intention of help-seeking from formal sources was relatively low. Therefore, the prevention of suicide required investment for creating a positive image of mental health care, which must be made accessible to the highest extent possible to the individuals who need to seek help from formal sources.

Keywords: Help-seeking, Suicide, Poisoned

\section{Conflict of Interest: No}

How to Cite: Inanlou M, Basiri SH, Zamani N, Haghani H. Help-seeking for Suicidal Thoughts in the Poisoned Patients at Loghman Hakim Teaching Hospital in Tehran, Iran. Iran Journal of Nursing. 2020; 32(122):91-106.

Received: 21 Nov 2019

Accepted: 17 Feb 2020 


\title{
يارى جويى براى افكار خودكشى در مسمومين مركز آموزشى درمانى لقمان حكيم تهران
}

\author{
مهرنوش اينانلو'، شقايق بصيرى '، نسيه زمانى'، حميد حقانىع
}

زمكيله و هدف: داشتن سابقه اقدام به خودكشى، مهمترين عامل خطر مرى بر اثر خودكشى است. يارى جويى مناسب، داراى توانايى محافظت از فرد در

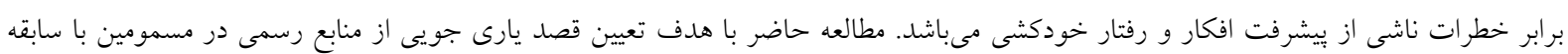

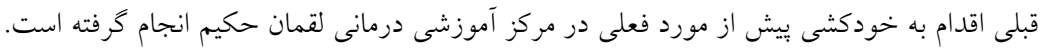

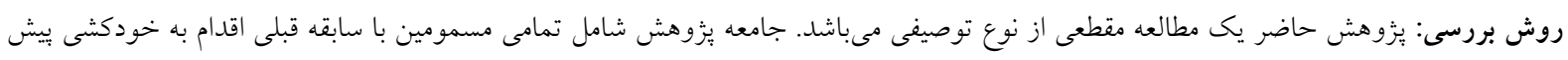

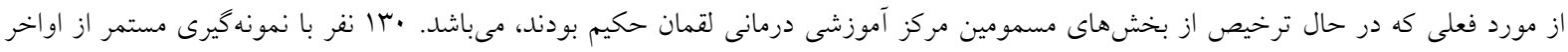

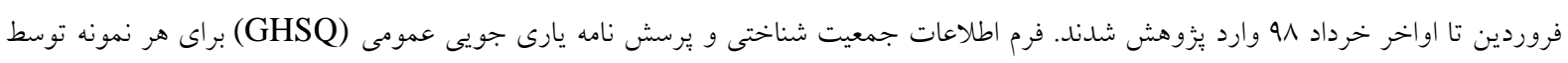

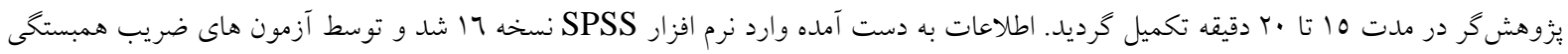

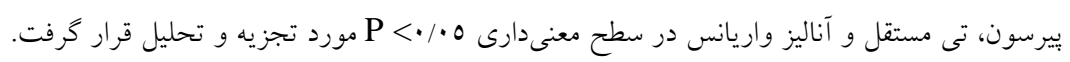

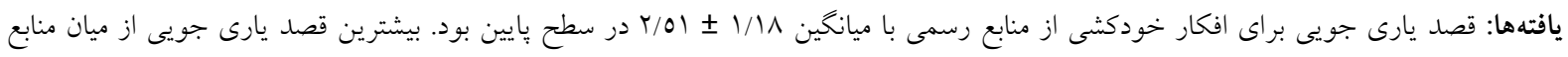

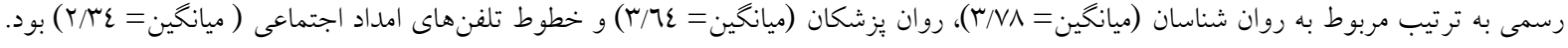

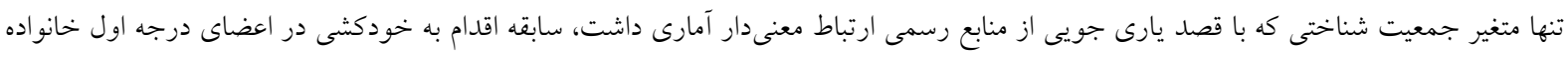
بود (P نتيجه گيرى كلى: قصد يارى جويى از منابع رسمى در افراد با سابقه اقدام به خودكشى مجدد، يايين بود. از آن جا كه يارى جويى يكى راهكار مقابلهاى

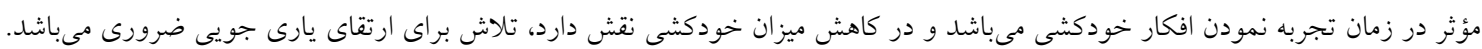

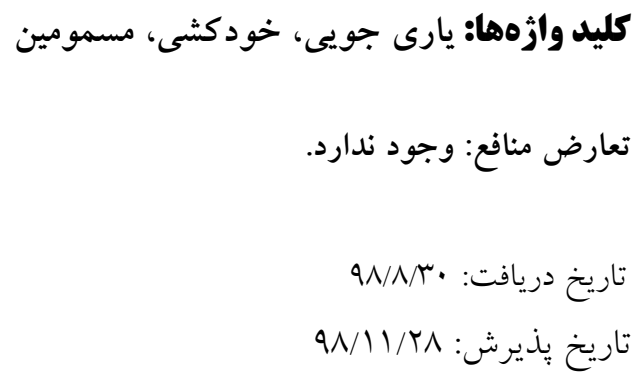

شماره تماس:

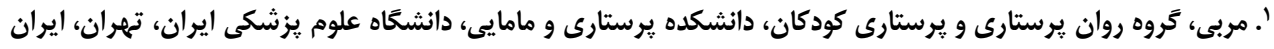

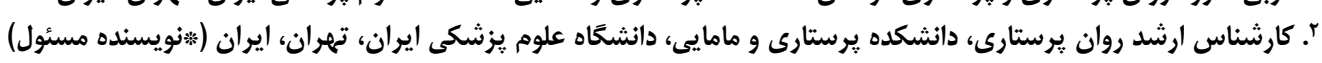


ارائه دهند كان مراقبت بهداشتى علائم را شناسايى كنند و

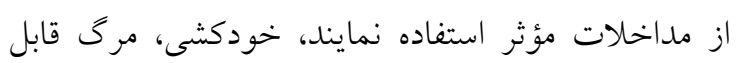

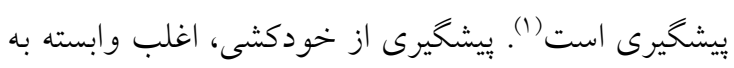

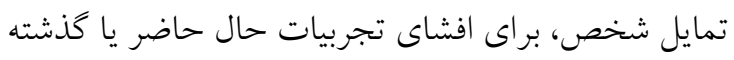

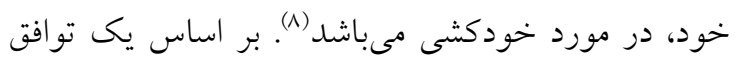

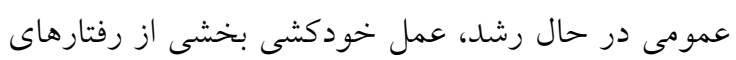

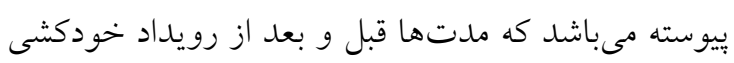

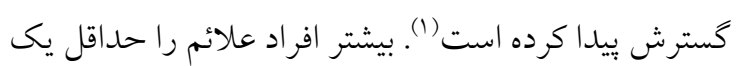
سال و افكار خودكشى را از مدتى قبل تجربه نمودهاند (7). ولى با وجود طول مدت و شدت علائم، افراد افكار

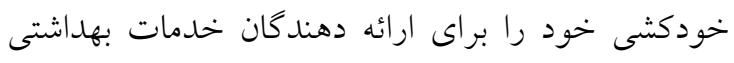

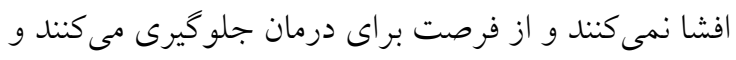

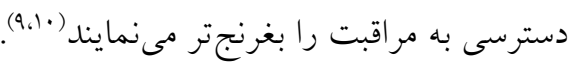

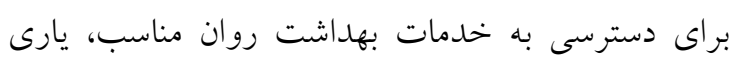

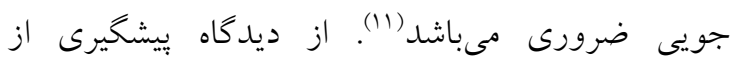
خودكشى، يارى جويى مناسب، داراى توانايى محافظت از

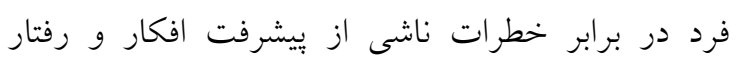
خودكشى مىباشد. مشخص شده است كه يارى جويى از

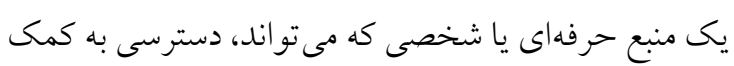

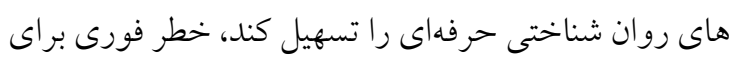

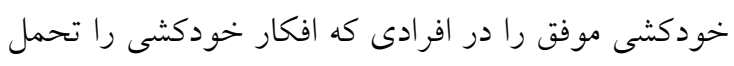

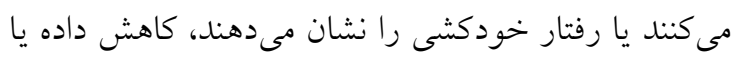

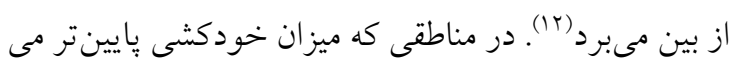
باشد، ميزان يارى جويى بيشتر است (rا). اما شواهد نشان

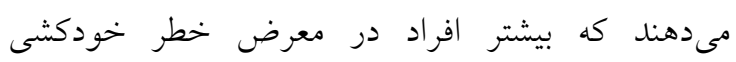
مخصوصاً افرادى كه سابقه خودكشى دارند، به دنبال يارى جويى نيستند (1). اعتقاد شخص مبنى بر اين كه افكار خودكشى، ضعف ئس

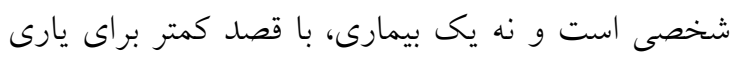

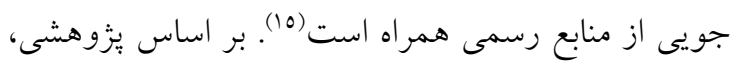

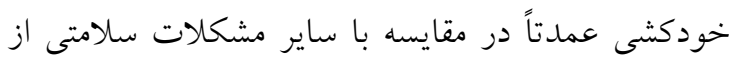

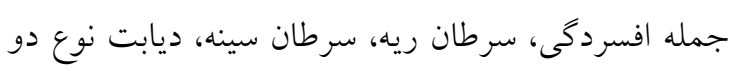

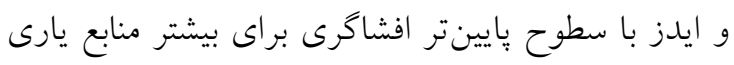

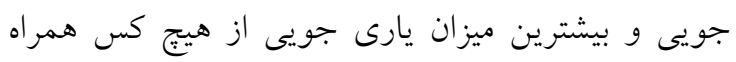

مقدمه

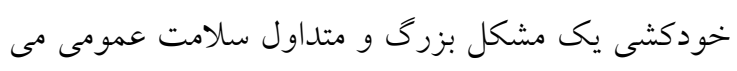

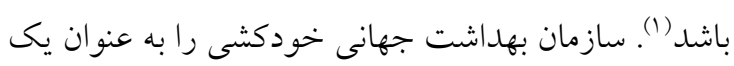

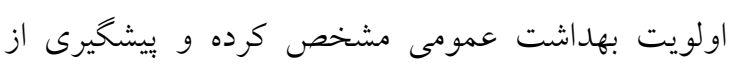
خودكشى را يك ضرورت در تمام كشورهاى جهان عنوان نموده است. در سراسر جهان هر سال هشتصد هزار نفر به علت خودكشى جان خود را از دست مىدهند. خودكشى در هر زمانى از جرخه زندگى مى تواند اتفاق بيفتد و دومين علت مرگ در ميان افراد و؟-10 ساله در جهان است (r). مرك بر اثر خودكشى جزء • ا علت اصلى مرگ و جزء .1 علت اصلى سالهاى از دست رفته عمر در بسيارى از

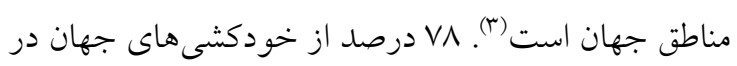
كشورهاى با درآمد كم و متوسط اتفاق مى افتد (r). بر اساس هاس آمار مؤسسه سنجش و ارزيابى سلامت (IHME)، ميزان

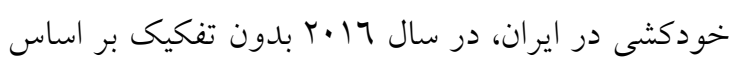
جنسيت و سن، T/17 نفر در هر صد هزار نفر و براى مردان

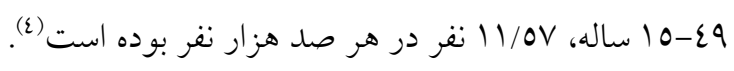
علاوه بر آمار مرگ و مير ناشى از خودكشى، به ازاى هر

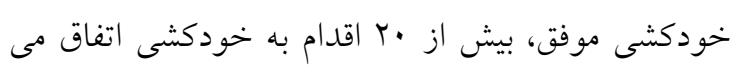

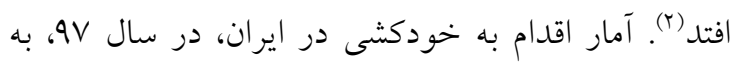

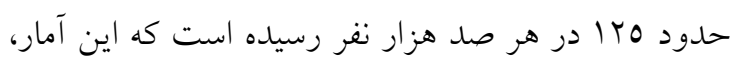

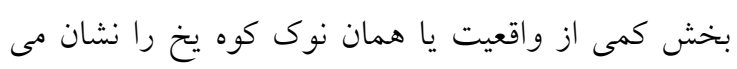
دهل (0). داشتن افكار و ييشينه اقدام به خودكشى، به تنهايى مهم

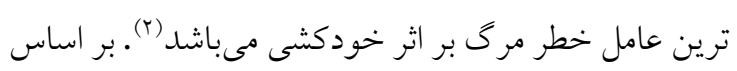

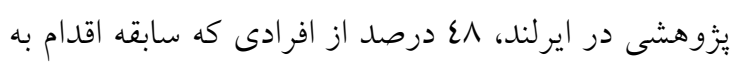

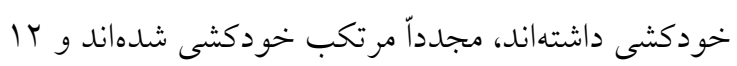
درصد از اين افراد نيز بر اثر خودكشى مجدد، جان خود را

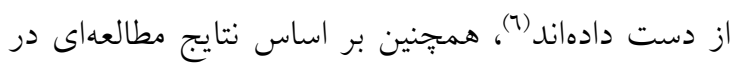
ايران نيز Tr/V درصد افرادى كه به دليل اقدام به خودكشى

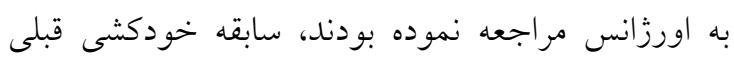

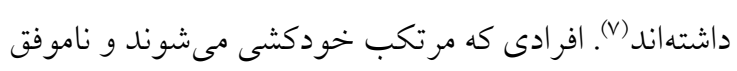
هستند، احتمال دارد كه بلدون درمان، مجدداً سعى بر

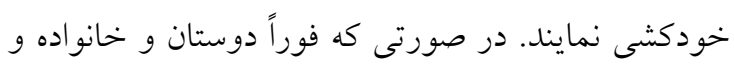


نتايج يزوهش هاى معلدود در افرادى كه تجربه خودكشى

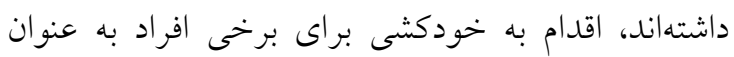

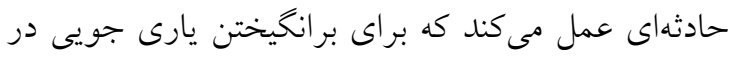

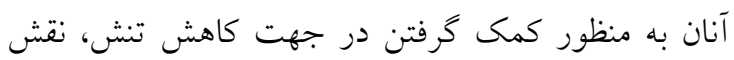

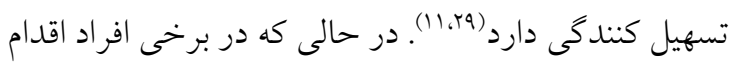
به خودكشى به عنوان مانعى براى يارى جويى عمل مى

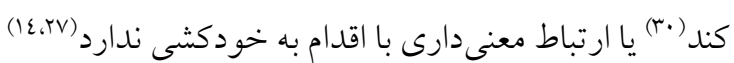
و لذا نتايج مطالعات نيز ضد و نقيض هستند. از سويى ديخر، يارى جويى تنها با ساختار شخصيتى افراد ارتباط ندارد بلكه تحقيقات نشان دادهاند كه بين مناطق

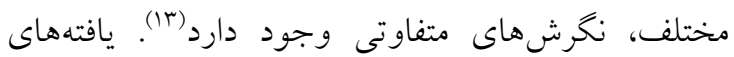
مطالعات مرورى نشان مىدهند كه ارزشهاى فرهنگى خاص، مىتوانند موانع خاصى را براى يارى جويى در زمان

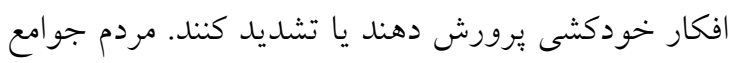

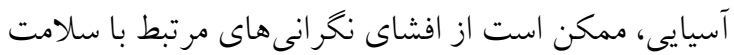

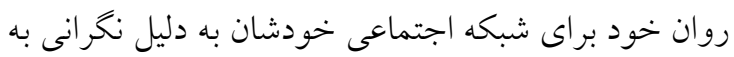

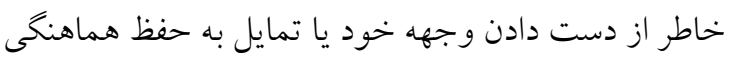

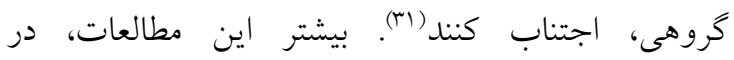

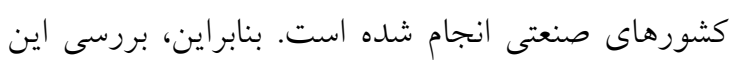

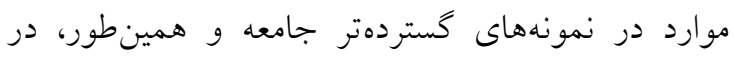
كشورهاى در حال توسعه، همراه با توجه به نقش زمينه

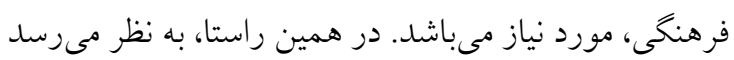

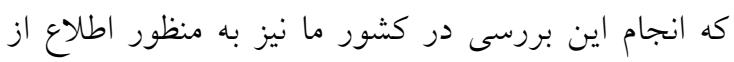

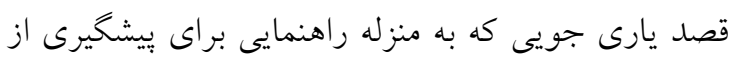

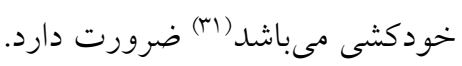

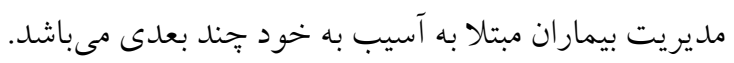
بنابراين روان يرستاران به عنوان افرادى كه داراى بالاترين سطح تماس با اين مددجويان مىباشند مىتواند نقشهاى

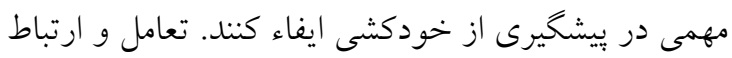
بين افرادى كه اقدام به خودكشى نمودهاند با يرستار،

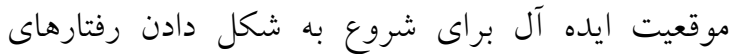
اجتماعى مىباشد كه در طول دورههاى دلسردى يا بحران

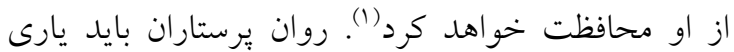
جويى را به عنوان يك راهبرد مقابلهاى مؤثر در زمان تجربه
بوده است (17). هم:جنين در مطالعهاى كه بر روى نوجوانان

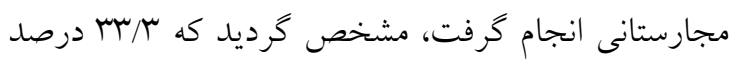

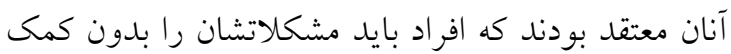

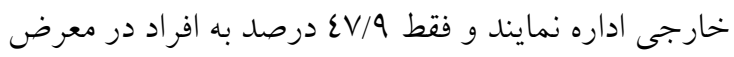
خودكشى توصيه مى كردند كه به متخصصان بهداشت روان

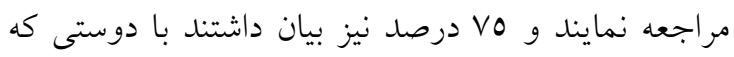
قصد خودكشى دارد به تنهايى صحبت خواهند كرد (IV). بر اساس يزّوهشى كه در مردان كشور ايرلند صورت يذيرفت، اغلب مردانى كه خودكشى كرده بودند، بيمارستان را بدون اين كه توسط تيم روان بزشكى ارزيابى شوند ترى

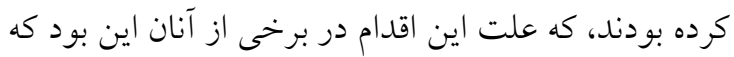

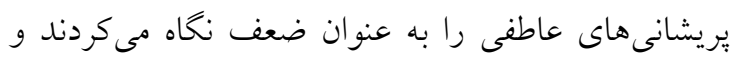
نكران برجسب خوردن توسط مردان ديخر بودند (7).

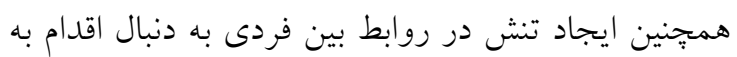
خودكشى، بر احساسات افراد در معرض خطر خودكشى لهى

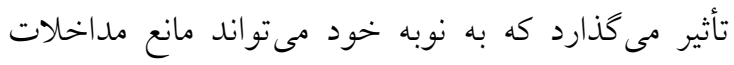

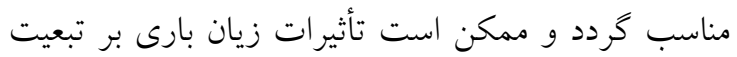

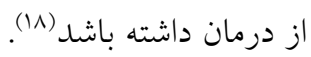
با وجود اهميت يارى جويى، اما بيشتر مطالعات در حوزه دونه

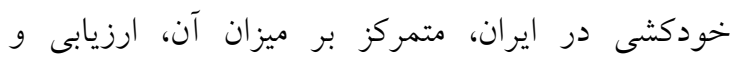

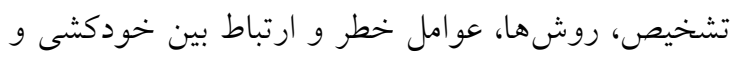

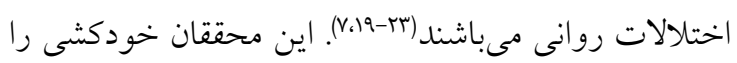
تنها به عنوان يكى رويداد و نه يكى روند ادامهدار مشاهده مى كنند. در ساير كشورها با هدف تعيين قصد يارى جويى

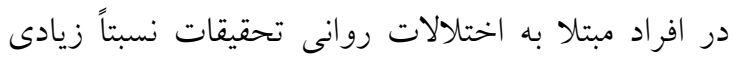

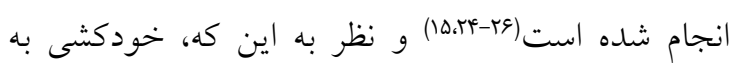

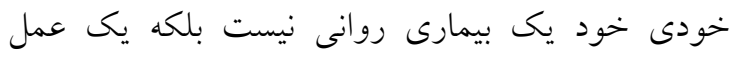

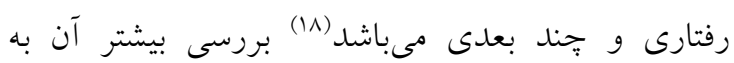
صورت جداكانه ضرورى است.

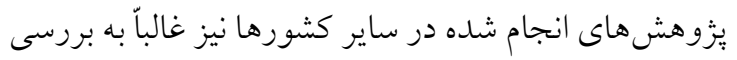
قصد يارى جويى بر روى جمعيت عمومى، دانشجويان و دانش آموزان يرداختهاند. در حقيقت، اين تحقيقات، يارى بئرئ

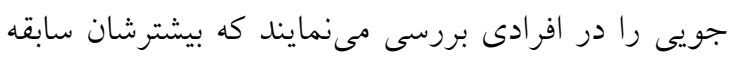

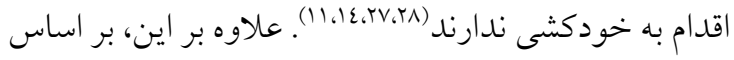


اواخر خرداد سال لهو و تقريباً به مدت دو ماه با نمونه كيرى

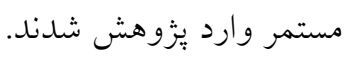

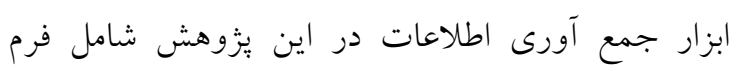

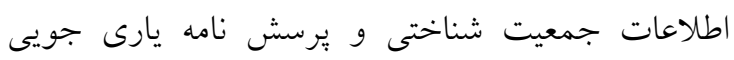

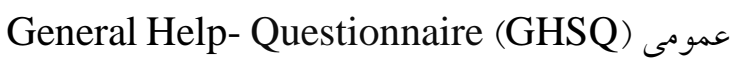
بود. فرم اطلاعات جمعيت شناختى شامل Seeking جنسيت، سن، تحصيلات، وضعيت تأهل، وضعيت اشتغال،

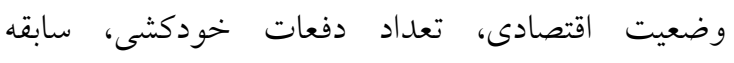
خانو ادكى خودكشى در اعضاى درجه اول خانو اده ، سابقه استفاده از خدمات مشاوره و روان شناسى، سابقه استفاده از داروهاى روان يزشكى تحت نظر يزشك و سابقه بسترى

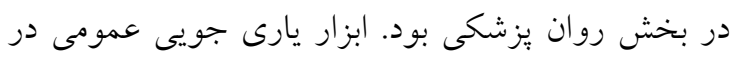

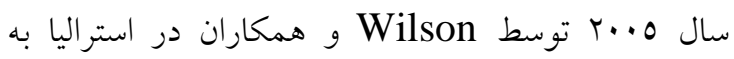
منظور سنجش مقاصد يارى جويى طراحى شده است. اين

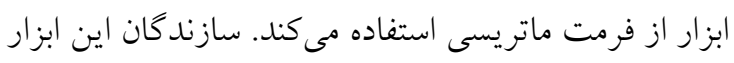

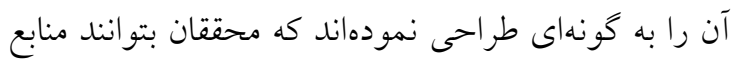

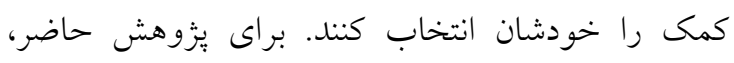
ليستى از هفت منبع رسمى بالقوه يارى جويى (روان

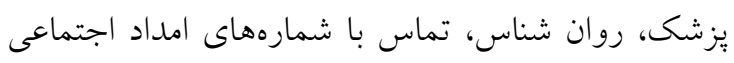

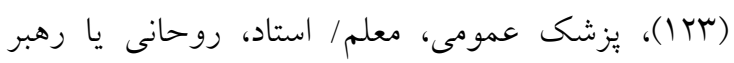

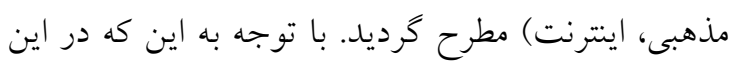

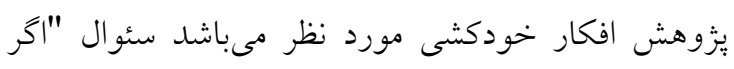
شما مجدداّ افكار خودكشى داشته باشيد، جِقدر اين احتمال

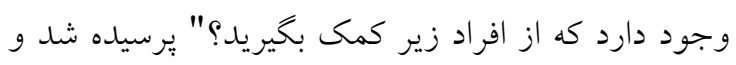

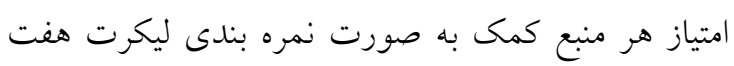

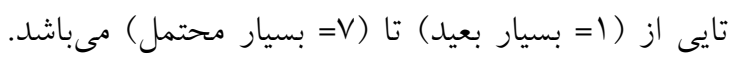

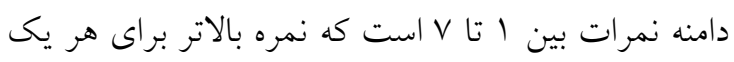
از منابع نشانه قصد بيشترى براى كمى كرفتن از آن منبع

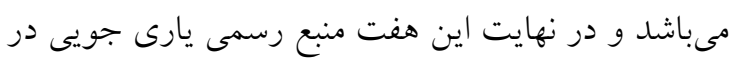
يكى دسته قرار داده شد كه نمره كل شامل ميانخين امتيازات داده شده به هر يك از منابع مىباشد (rr).

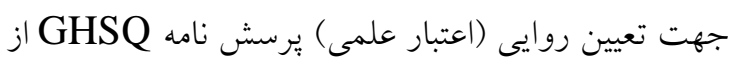

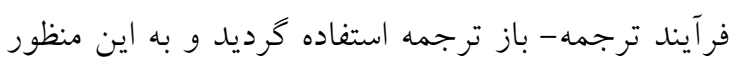
در ابتدا ابزار به دو مترجم زبان انحليسى و آشنا به مفاهيم
نمودن افكار خودكشى (ז) در افراد توسعه دهند و با ارزيابى قصد يارى جويى اشخاص براى افكار خودكشى منابع ترجيحى كمك را شناسايى نمايند (rr).

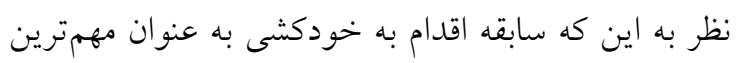

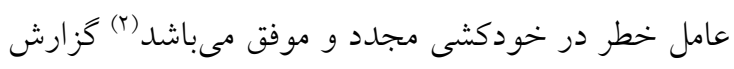

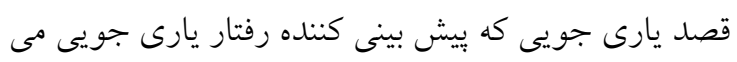

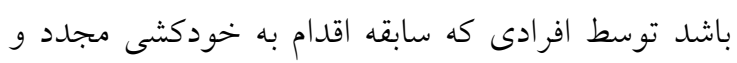

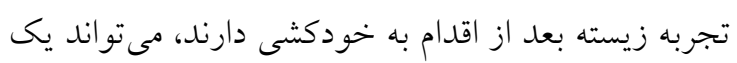

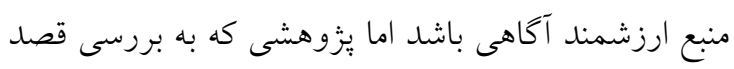

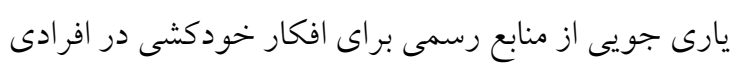

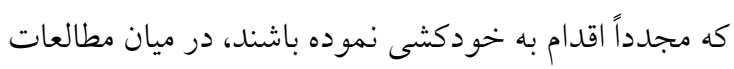

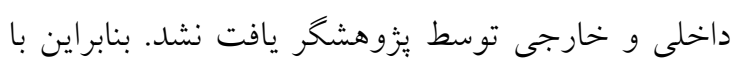
توجه به اهميت موضوع يارى جويى در بيشخيرى از

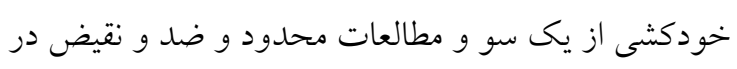

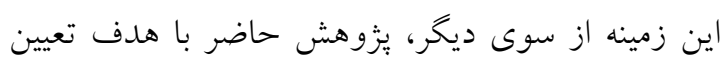
قصد يارى جويى از منابع رسمى و ارتباط آن با عوامل دئه

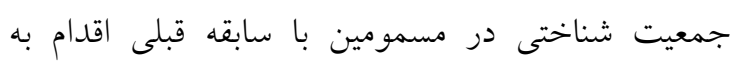

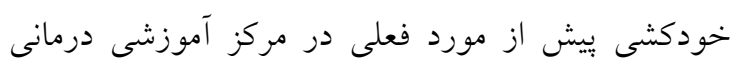
لقمان حكيم طر احى و اجرا شد.

يزّوهش حاضر يكى مطالعه مقطعى از نوع توصيفى مى باشد.

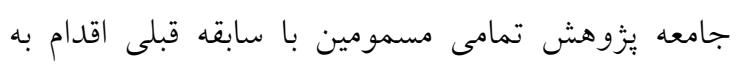

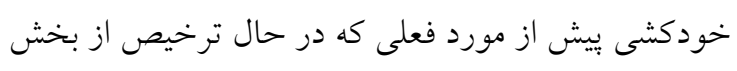

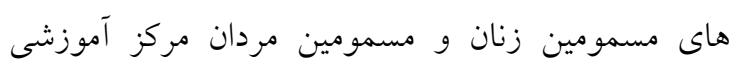

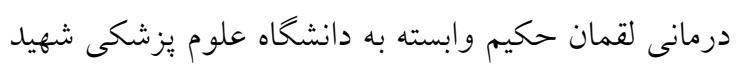

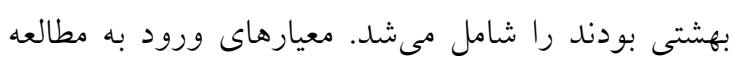

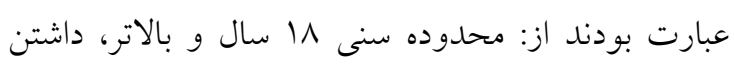

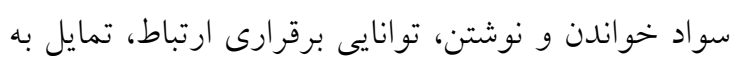

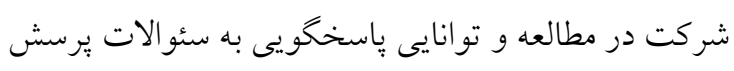

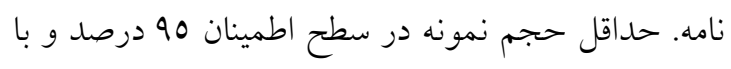

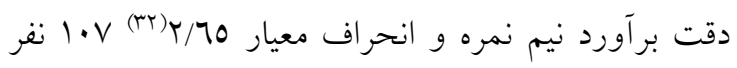

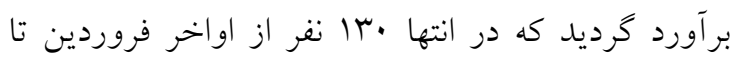


نمونه مورد نظر در اين مطالعه افراد در حال ترخيص بودند،

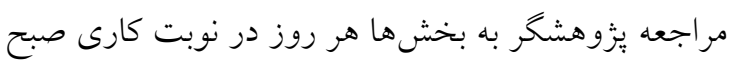

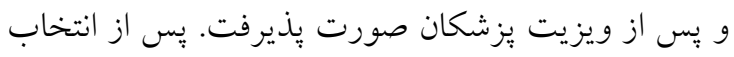

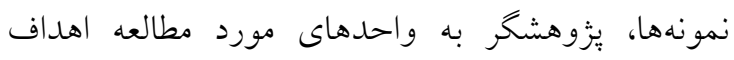

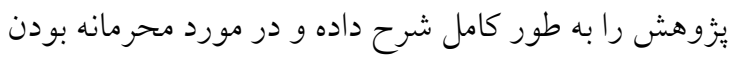
اطلاعات شخصى به ايشان اطمينان داد. در صورت تمايل

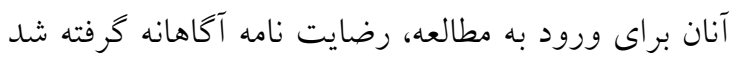
و يرسش نامه و نحوه ياسخدهى به آن به طور دقيق توضيح

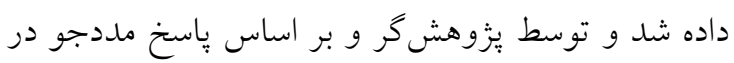

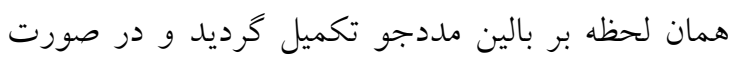

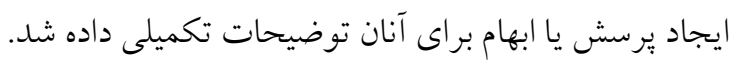

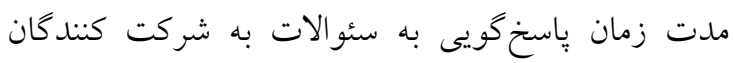

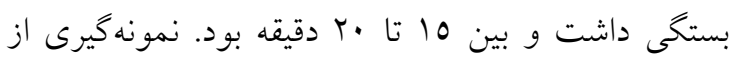

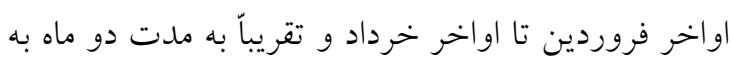
طول انجاميد. در نهايت، · با عدد يرسشنامه كه به طور كامل تكميل شده

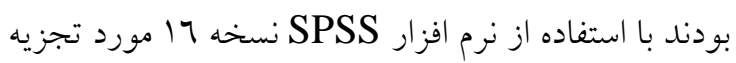

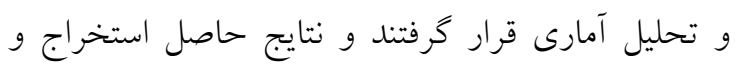

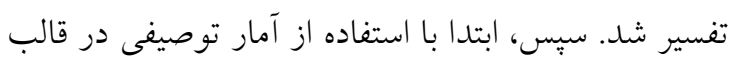

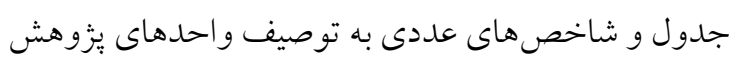
يرداخته شد و جهت تعيين ارتباط بين متغيرهاى جمعيت

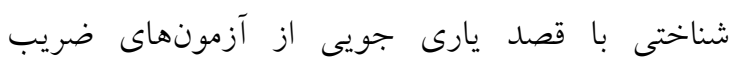

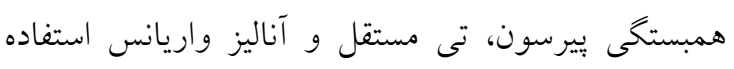

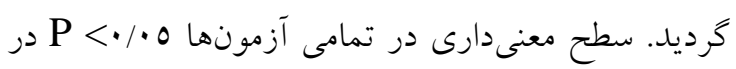

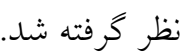

\section{يافتهها}

نتايج اين مطالعه نشان داد كه سن واحدهاى مورد مطالعه

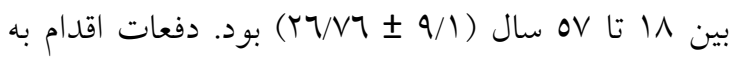
خودكشى در واحدهاى مورد مطالعه بين r تا عا مرتبه

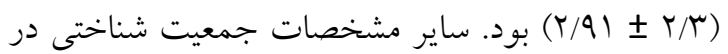

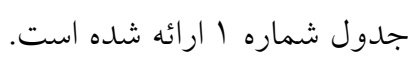

يزشكى داده شد كه آنها را به فارسى ترجمه نمودند و سبس متن ترجمه شده توسط مترجم ديخرى به زبان

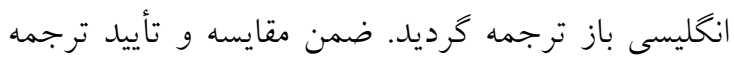

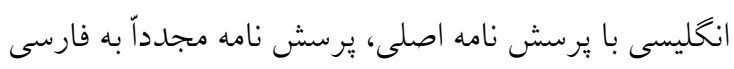

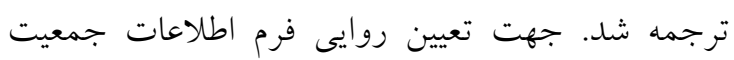

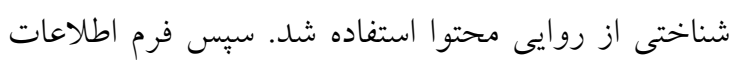
جمعيت شناختى و يرسش نامه يارى جويى عمومى در

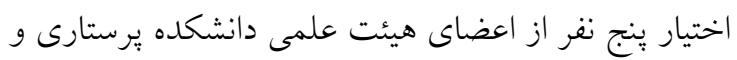
مامايى ايران قرار داده شد و نظرات اصلاحى ايشان اعمال

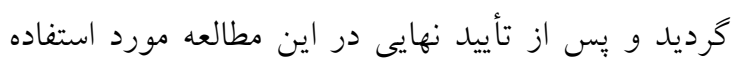
قرار كرفت. و و همكاران در مطالعهاى در زمينه افكار

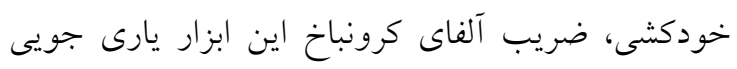

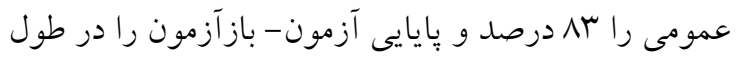

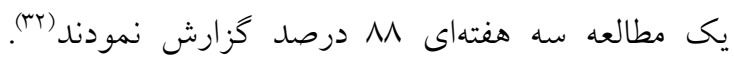
يlivari and Guzman-Gonzalez

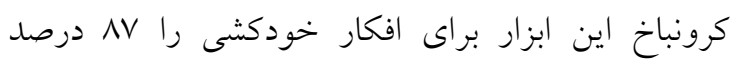

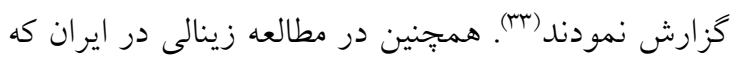

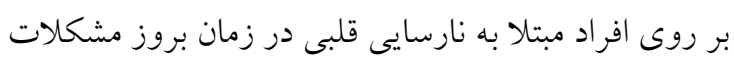

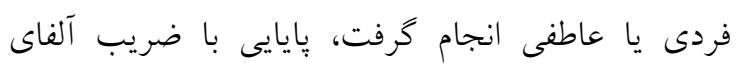

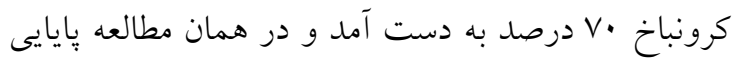

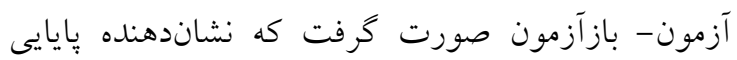

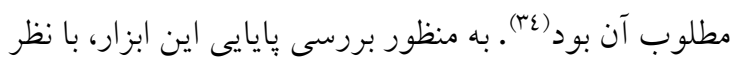

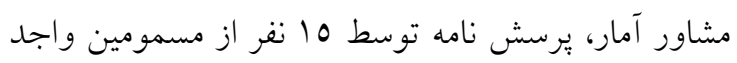

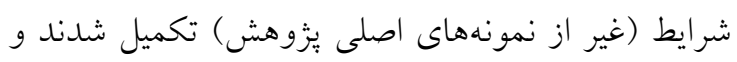

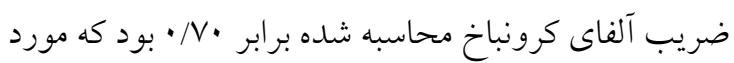
تأييد قرار كرفت. پِ از تصويب يرويوزال و كسب تأييديه كميته اخلاق دانشكاه علوم يزشكى ايران (IR.IUMS.REC.1397.791)

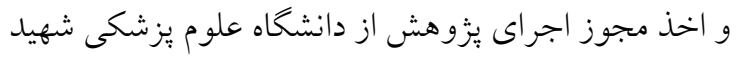
بهشتى، به مركز آموزشى درمانى لقمان حكيم مراجعه و و برونس

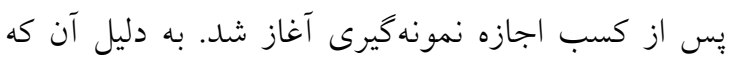


جدول ا: مشخصات جمعيت شناختى شر كت كنندكان و شاخص هاى عددى قصد يارى جويى از منابع رسمى بر حسب مشخصات جمعيت شناختى در افراد مورد مطالعه

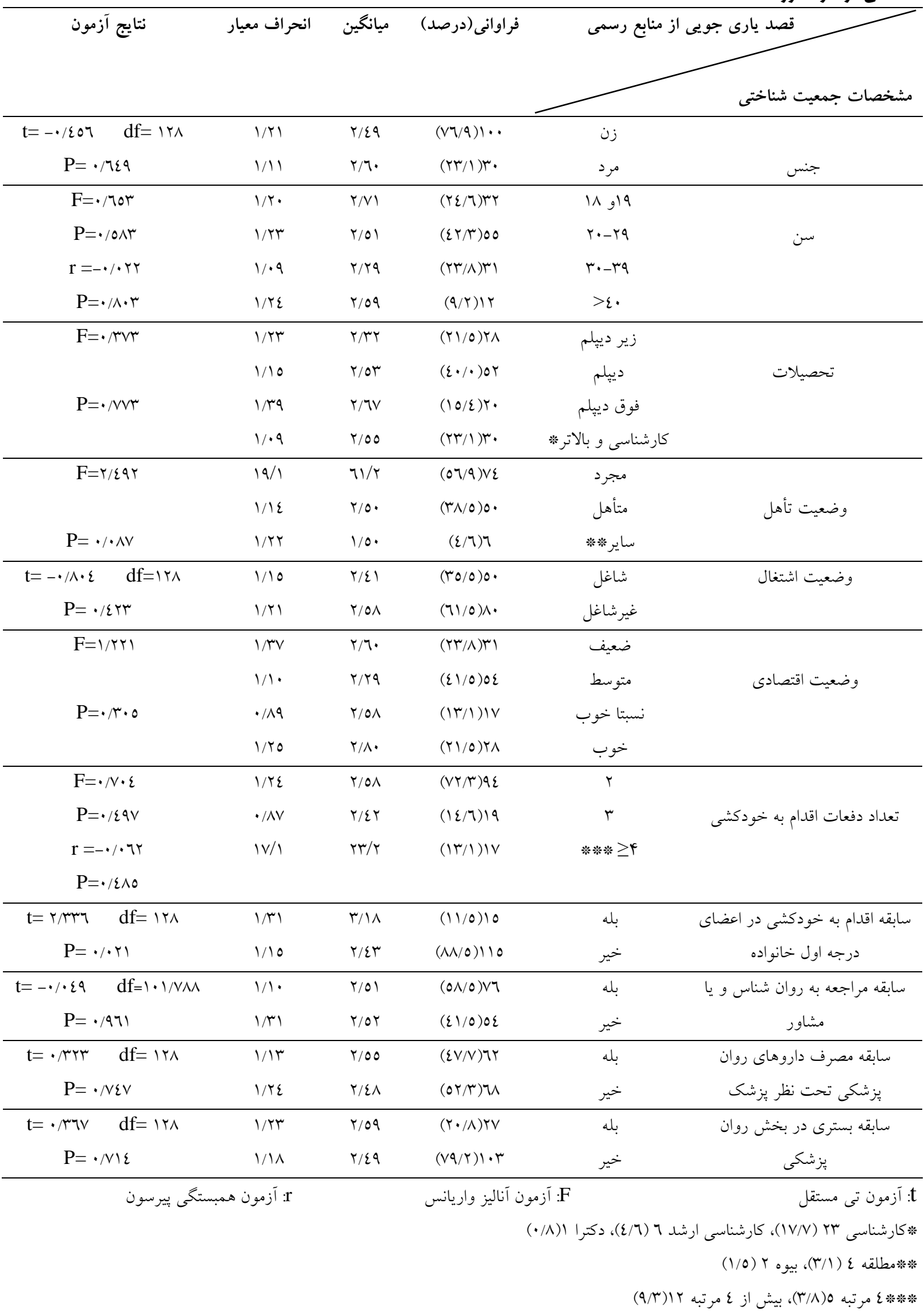


كه سابقه خانوادگى خودكشى داشته اند، بيشتر بود (جدول

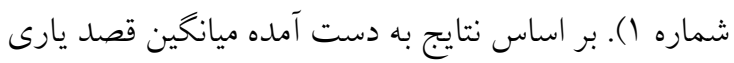

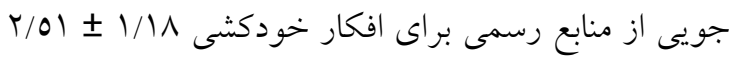

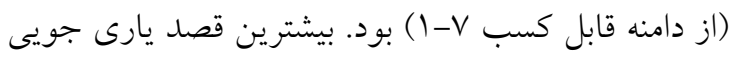

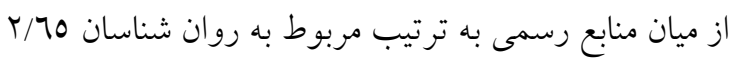

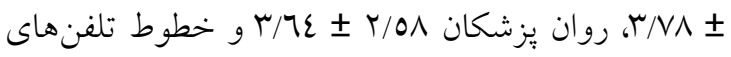

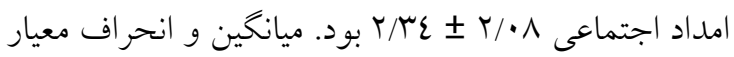
قصد يارى جويى از منابع رسمى در جدول شماره ب ارائه شلده است.
از ميان متغيرهاى جمعيت شناختى، قصد يارى جويى از منابع رسمى با جنس، سن، تحصيلات، وضعيت تأهل،

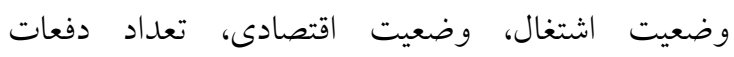
خودكشى، سابقه استفاده از خدمات مشاوره و وروان شناسى، سابقه استفاده از داروهاى روان يز شكى تحت نظ نظر

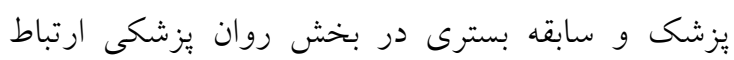

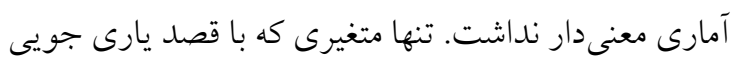
از منابع رسمى ارتباط معنى دار آمارى داشت، سابقه اقدام

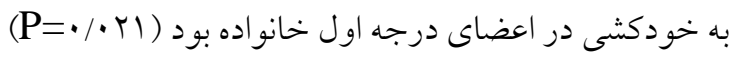
و ميانخين نمره قصد يارى جويى از منابع رسمى در افرادى

جدول شماره r: شاخصهاى عددى قصد يارى جويى از منابع رسمى در افراد مورد مطالعه

\begin{tabular}{|c|c|c|c|c|}
\hline انحر اف معيار & 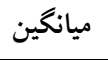 & بيشنه & كمينه & 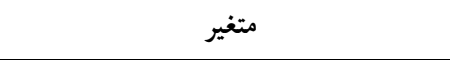 \\
\hline $1 / 11$ & $r / 01$ & $0 / 1 \varepsilon$ & 1 & قصد يارى جويى از منابع رسمى \\
\hline$r / \cdot \wedge$ & $\tau / \mu \varepsilon$ & $\checkmark$ & 1 & تماس با شمارههاى امداد اجتماعى ( Tr I) \\
\hline $1 / 90$ & $r / \cdot \varepsilon$ & v & 1 & يز شيك عمومى \\
\hline$r / 01$ & $r / \neg \varepsilon$ & $\checkmark$ & 1 & روان يزشى \\
\hline$r / 70$ & r/v^ & v & 1 & 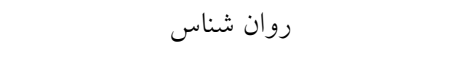 \\
\hline $1 / M$ & $1 / 91$ & v & 1 & 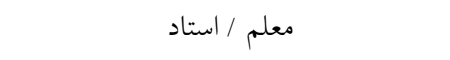 \\
\hline $1 / V 7$ & $1 / N r$ & v & 1 & روحانى يا رهبر مذهبى \\
\hline$T / T \Lambda$ & $r / \ell$ & $\checkmark$ & 1 & ايتترنت \\
\hline
\end{tabular}

شد و همخى قصد يارى جويى از منابع رسمى در زمان

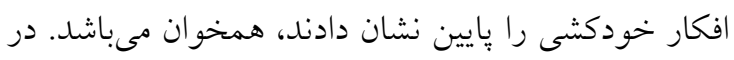

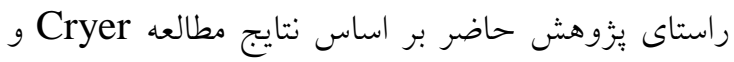

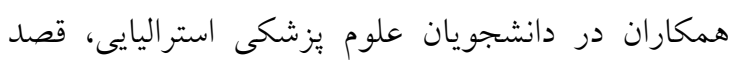

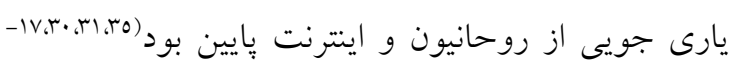

نتايج اين يُزوهش با نتايج مطالعه Kearns و همكاران در

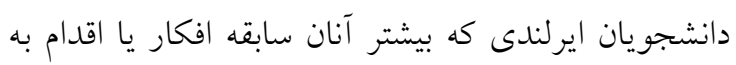
خودكشى داشتند كه تجربه يارى جويى از منابع رسمى را

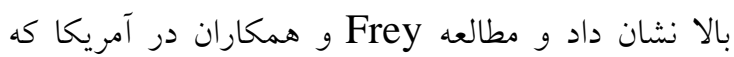
ميزان تماس با منابع يارى جويى رسمى در افرادى كه سابقه ونه

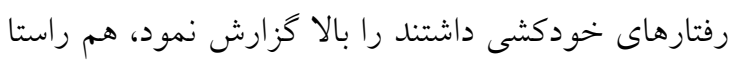

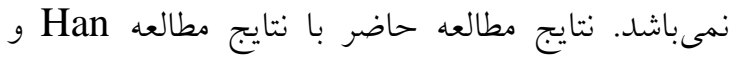
همكاران در دانشجويان جينى و استراليايى، Chan و

\section{بحث و نتيجه كيرى}

بر اساس نتايج به دست آمده ميانخين قصد يارى جويى از

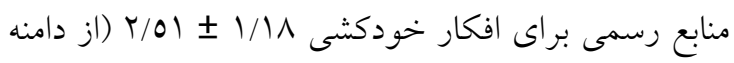

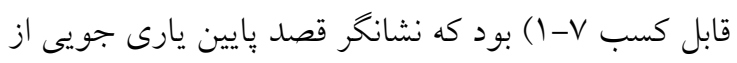

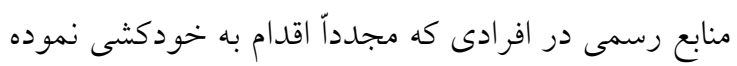

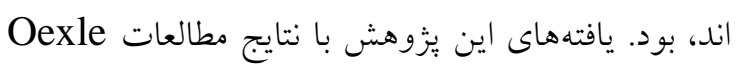

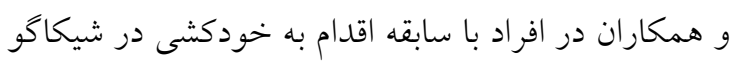
آمريكا، Wilks و همكاران در جمعيت عمومى بزر كسالان

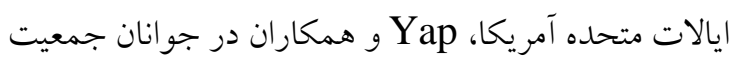

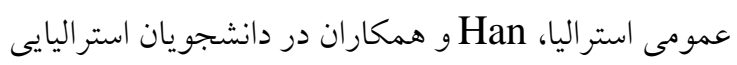

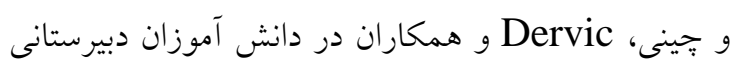
كشور مجارستان و نتايج مرور نظاممند مطالعات يارى جويى در جوانان با افكار يا سابقه اقدام به خودكشى جامعند بين الملل كه توسط Michelmore و Hindley انجام 
است. مسأله قابل يذيرش بودن خودكشى در جوامع، كاملاً

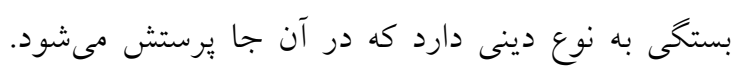

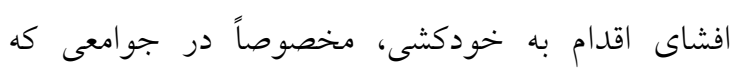

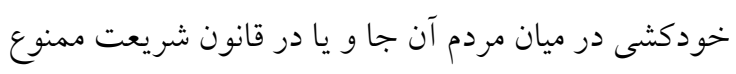

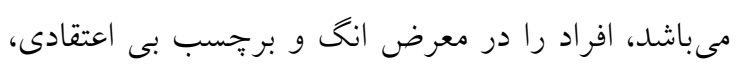

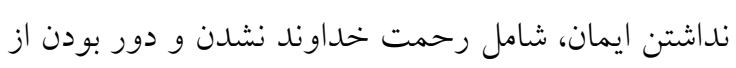

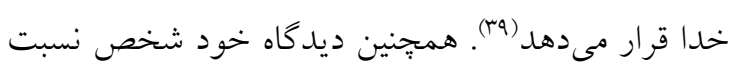
به خودكشى نيز بر قصد يارى جويى تأثير گذار است.

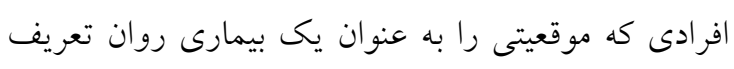

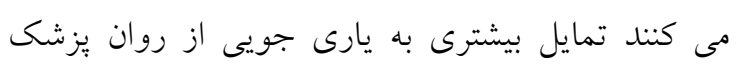
دارند (ra) قصد يارى جويى از هر منبع، بازتاب طرز برخوردهاى اين

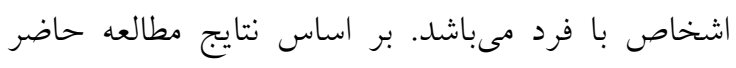

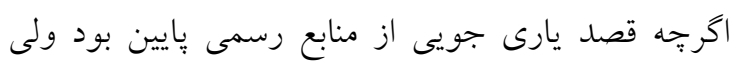

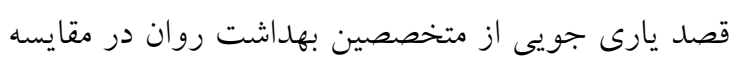

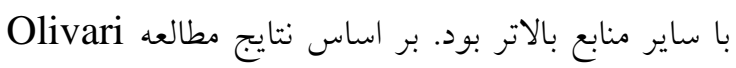

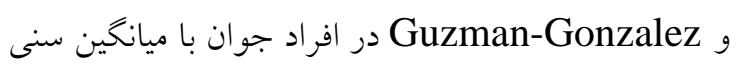
IV

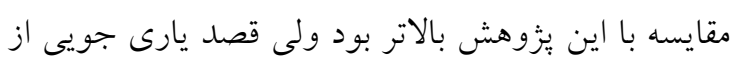

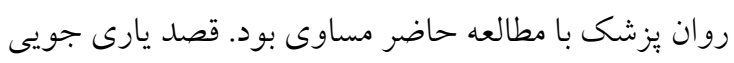
در يزوهش حاضر در مقايسه با مطالعه Han و همكاران

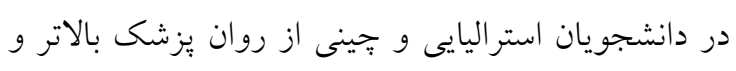
در مقايسه با مطالعه Barney و همكاران در بزرخسالان

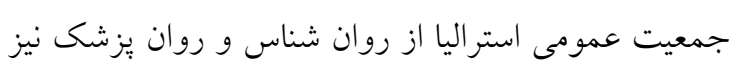

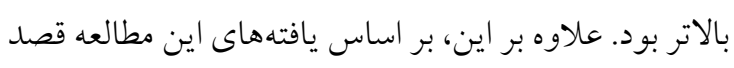

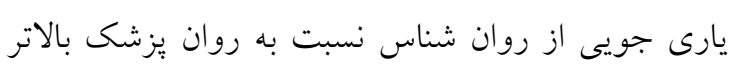

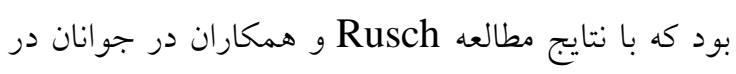
معرض خطر سايكوز در سوييس، Barney و همكاران،

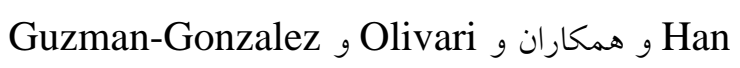

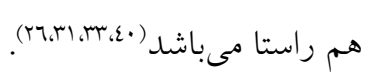

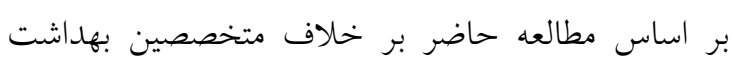

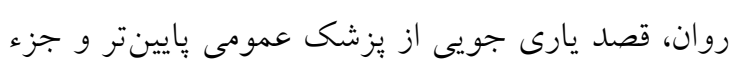

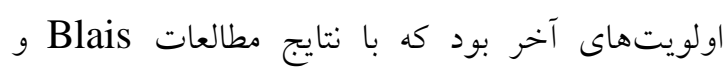
Renshaw

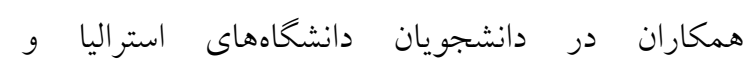
Hollinger

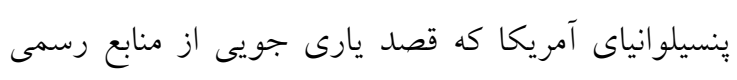

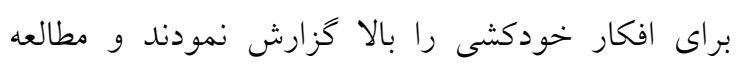
Calear كه نشان داد قصد يارى جويى از منابع رسمى در زمان افكار خودكشى در سطح متوسط بود هم راستا نمىباشد.

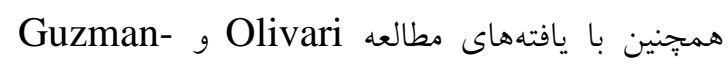
Gonzalez شيلى كه ميانخين قصد يارى جويى از منابع رسمى براى

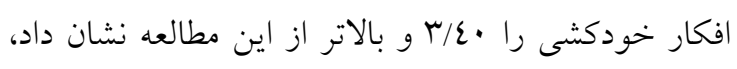

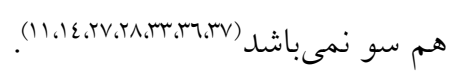

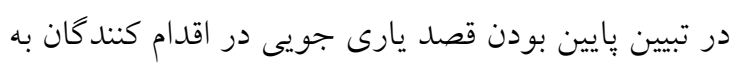

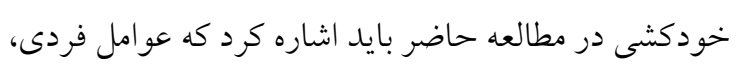

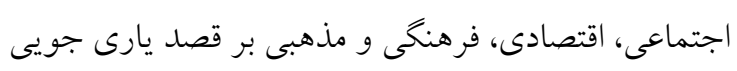

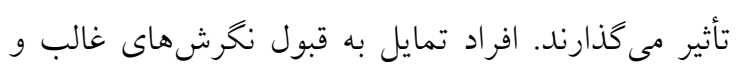

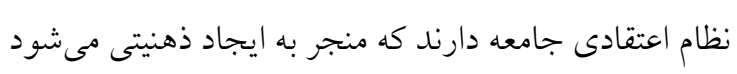

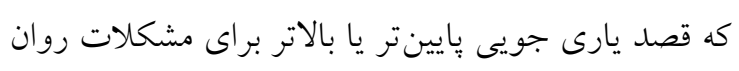

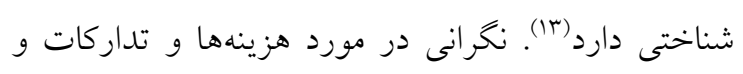

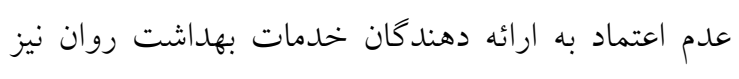

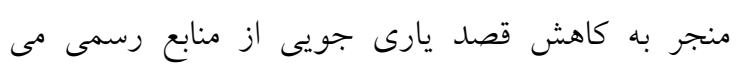

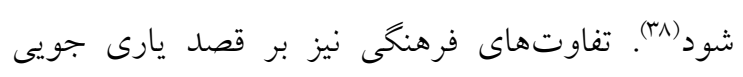

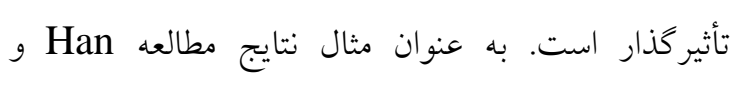

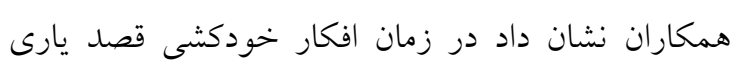
جويى از منابع رسمى در دانشجويان جينى از استراليايى ناني

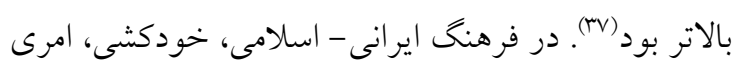

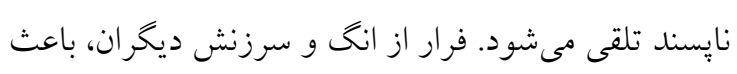

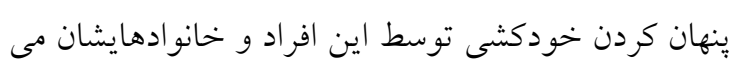

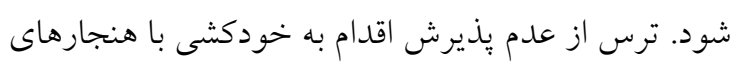
اجتماعى مرتبط است. در برخى جوامع، برخى رفتارها غيرقابل وذيرش است و هيج جيزى نمى تواند اين اقدامات

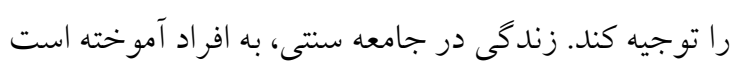
كه شايعات منتشر مىشوند. اولين قضاوت افراد درباره زنان اقدام كننده به خودكشى، برجسب رابطه جنسى نامشروع 
مورد صلاحيت بالينى معلمان و اساتيد بر قصد يارى جويى

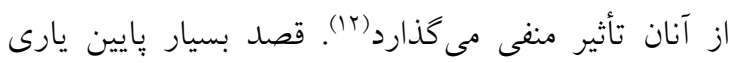

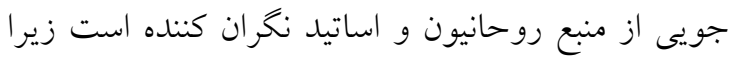
اين افراد مشوق، حمايت كننده و ارجاع دهنده و دروازه مراقبتهاى بهداشت روان تخصصى هستند. در مقايسه بين افكار خودكشى با ساير مشكلات هيجانى و

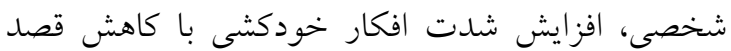
يارى جويى از منابع رسمى ارتباط معنى دار دارد ولى منجر به افزايش قصد يارى جويى از ايتترنت و خطوط تلفنهاى

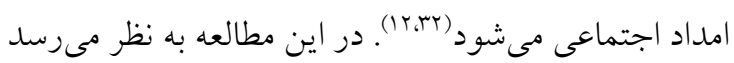
كه غنى و كارآمد نمودن محتواى سايتها و و شبكههاى اجتماعى فارسى زبان منجر به افزايش قصد يارى جويى از

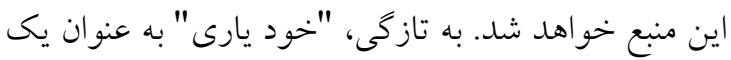

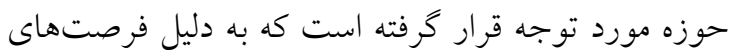
رو به رشد براى استفاده از فن آورىهاى ارتباطى مرتبط با

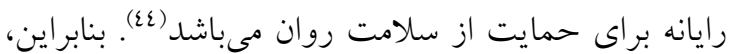
كمك مى تواند از منابعى كه نياز به تماس مستقيم با افراد

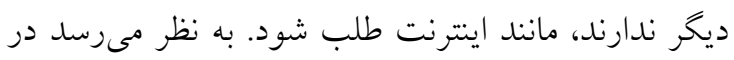

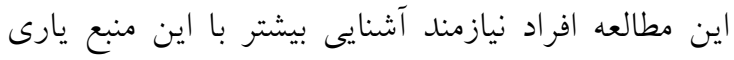

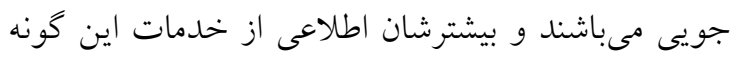
خطوط امدادى در بيشخيرى از خودكشى ندارند. از ميان عوامل جمعيت شناختى بين قصد يارى جويى از منابع رسمى با جنسيت، سن، تحصيلات، وضعيت تأهل، وضعيت اشتغال، وضعيت اقتصادى و تعداد دفعات خودكشى ارتباط معنىدار وجود نداشت و قصد يارى جويى از منابع رسمى در تمامى افراد دسته بندىهاى مختلف متغيرهاى مذكور پايين بود. اين يافته مىتواند

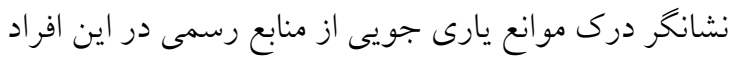
مانند احساس ناراحتى از مطرح كردن مشكلات با ديخران

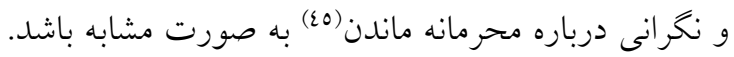
بر اساس نتايج مطالعه حاضر تنها متغيرى كه با قصد يارى

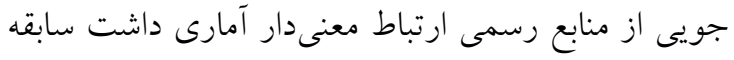

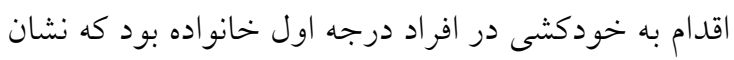

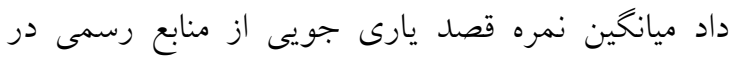

و و همكاران در دانش آموزان دبيرستانى استراليا و Calear كه به بالاتر بودن قصد يارى جويى از متخصصين سلامت

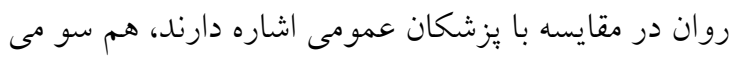

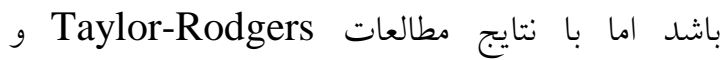
Batterham و Barney

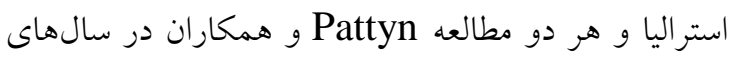
rا.r و ع ا.r در جمعيت عمومى بلزيك كه قصد يارى جويى از يزشك عمومى در مقايسه با روان شناس و روان

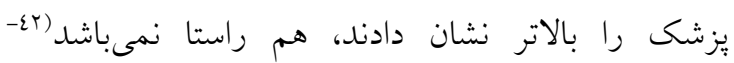

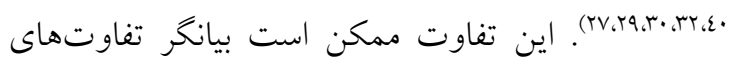

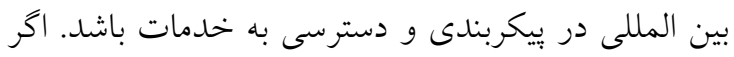

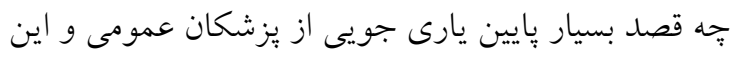

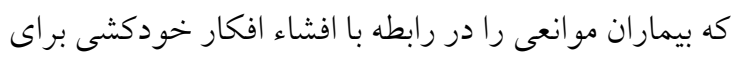

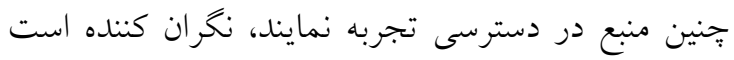

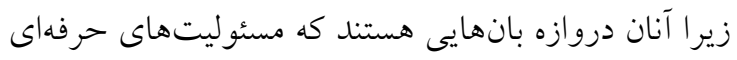

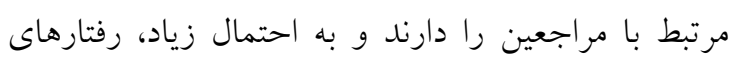
ارجاعى و قصد يارى جويى از منابع رسمى براى درمان را

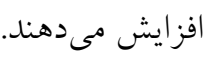
بر اساس نتايج مطالعه حاضر، بايينترين قصد يارى جويى ندي

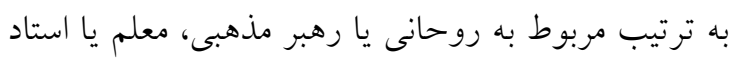

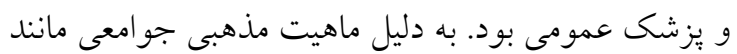

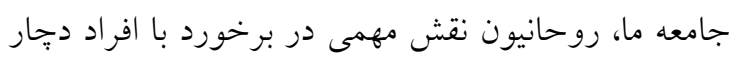

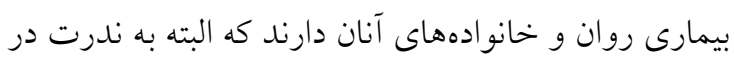
رسيدگى به موضوعات سلامت روان آموزش رسمى ديده

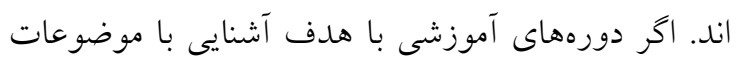
سلامت روان براى روحانيان طراحى و برگزار شود، آنها

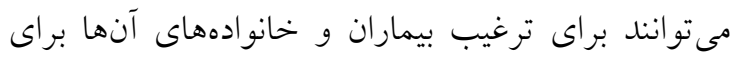

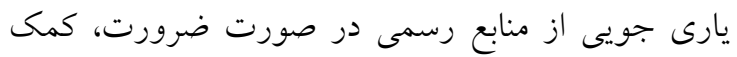

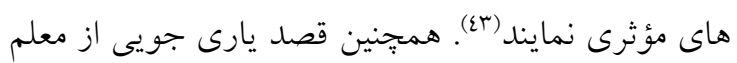
يا استاد در زمان افكار خودكشى در اين مطالعه در مقايسه

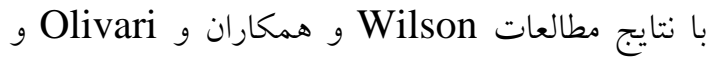
Guzman-Gonzalez 
براى بيشخيرى از خودكشى، سرمايه كذارى براى ايجاد يك

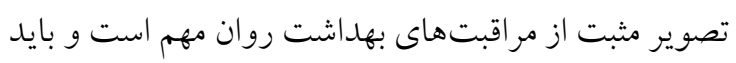

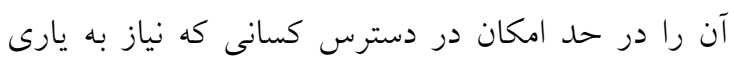
جويى از منابع رسمى دارند قرار داد. بر اساس نتايج يزوهش حاضر، قصد يارى جويى داريى از منابع

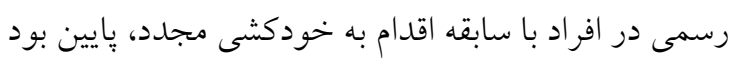

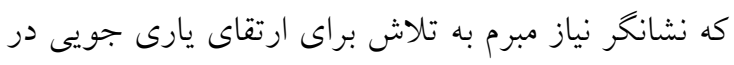

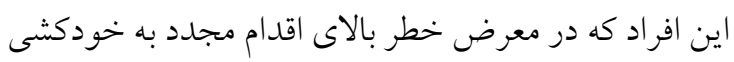

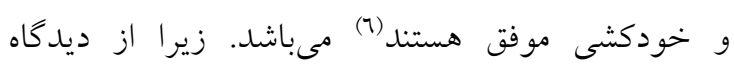
بيشخيرى از خودكشى، يارى جويى مناسب، داراى توانايى هونى

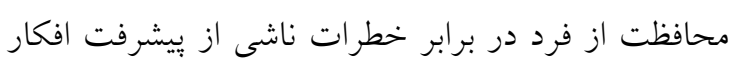
خودكشى مىباشد و دسترسى به كمكهاى روان شناختى

$$
\text { حرفهاى را تسهيل مى كند (ir). }
$$

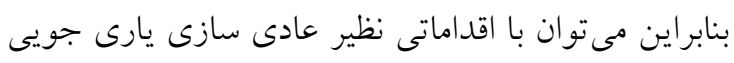

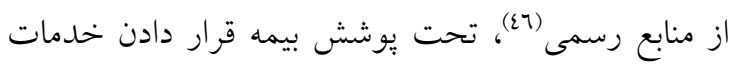
سلامت روان، تقويت مهارتهاى ارتباطى در خانو رداده افرادى كه سابقه خودكشى دارند به عنوان تسهيل كننده

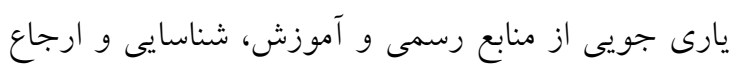

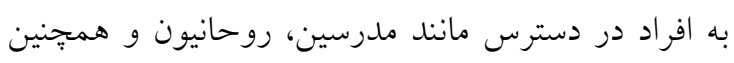

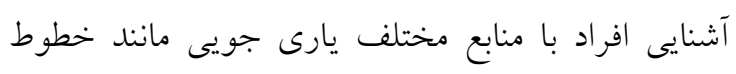

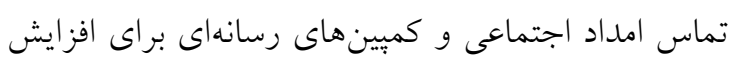

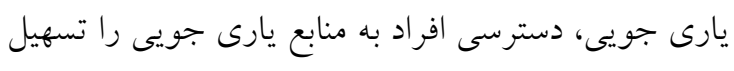

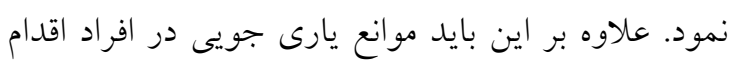

$$
\text { كننده به خودكشى شناسايى و رفع شوند. }
$$
بر خلاف بسيارى از عوامل عمده خطر خودكشى مانند

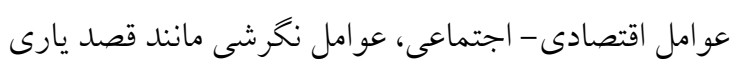

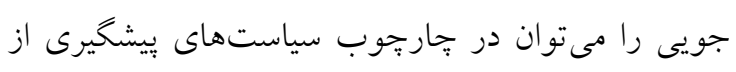
خودكشى با توجه به تفاوتهاى منطقه در راستاى افزايش دري

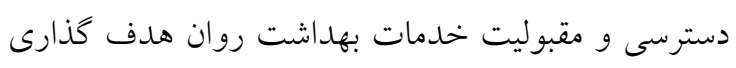

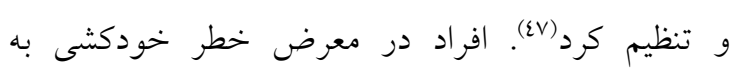

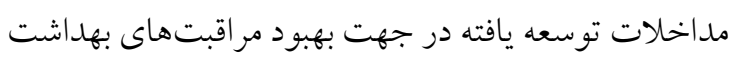

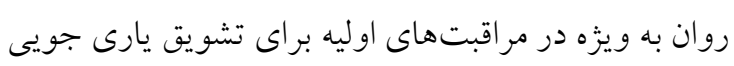

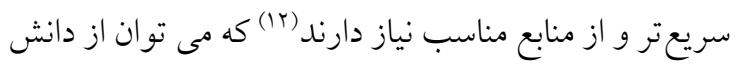
و مهارت كارشناسان ارشد روان تِرستارى در بيمارستان
افرادى كه سابقه خانوادگى خودكشى داشتهاند، بيشتر بود كه با نتايج مرور نظام مند مطالعات يارى جويى در جوانان

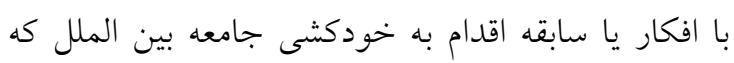

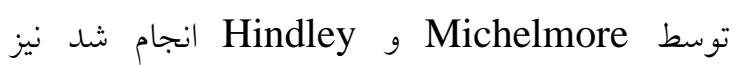

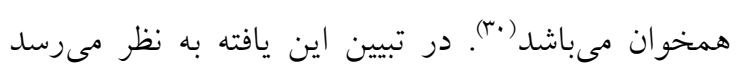

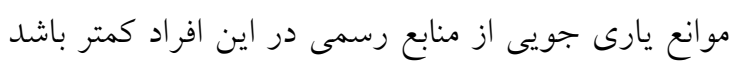

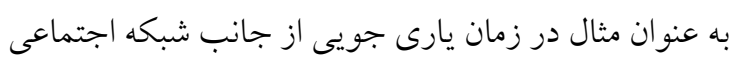
شان انح كمترى به آنان زده مى شود و يا شايد دليل ديخر

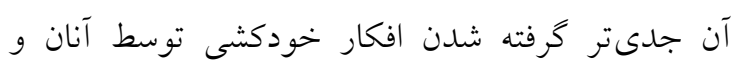

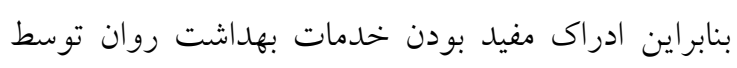
آنان باشد. همجنين بر اساس نتايج اين مطالعه، بين سابقه استفاده از خدمات مشاوره و روان شناسى، سابقه استفاده

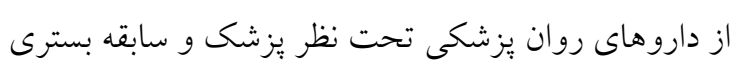

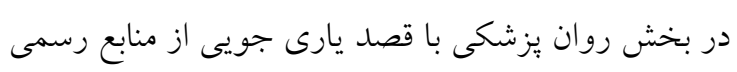

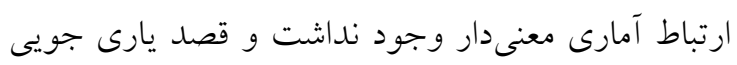

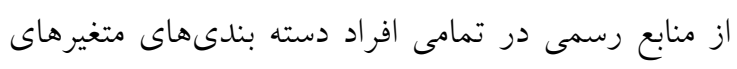

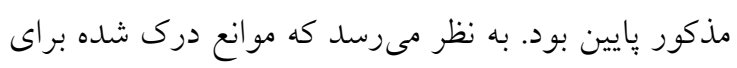

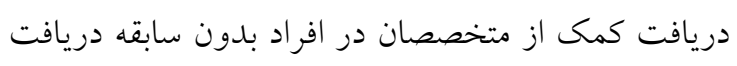

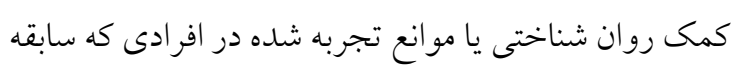

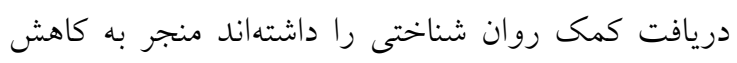
قصد يارى جويى رسمى شده است. در همين راستا نتايج

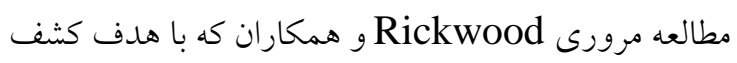

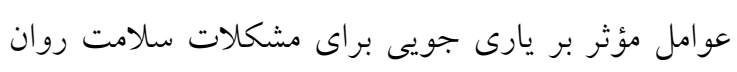

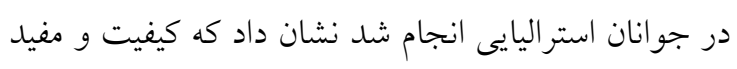

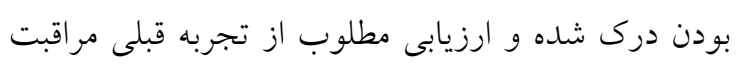

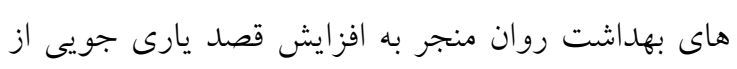

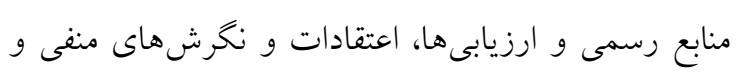

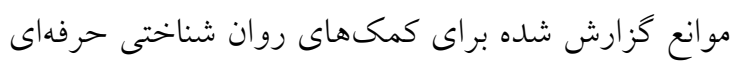

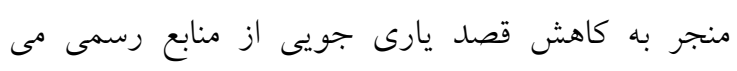
كردد در مطالعه حاضر فقط حدود نيمى از افرادى كه سابقه اقدام

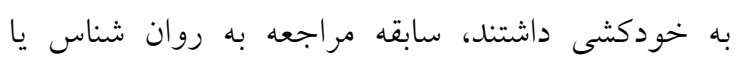

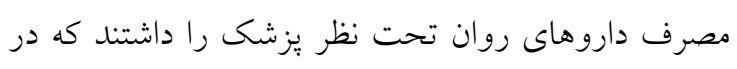
آنان نيز قصد يارى جويى از منابع رسمى هايين بود. بنابراين 
يزوهشگر سعى نمود پِ از برقرارى ارتباط با تشويق كلامى مشاركت آنان جلب شود. با توجه به تحقيقات محدود در زمينه قصد يارى جويى مليى

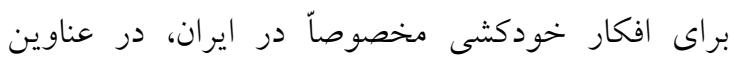
يزوهشى بايد به اين متغير بيش از بيش توجه شود.

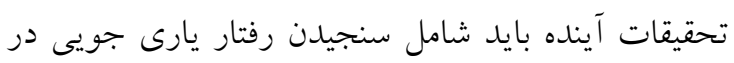

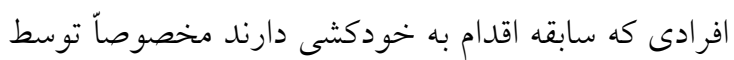
اقدامات طولى بلند مدت باشد. يزوهش حاضر براى

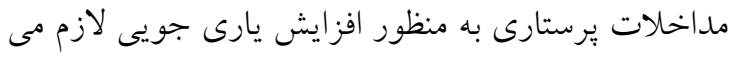
باشد و بايد مداخلاتى براى ارتقاى يارى جويى براى افكار

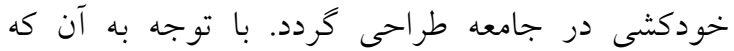
رسانهاى ديجيتال در حال تبديل شدن به ابزارى قدرتمند

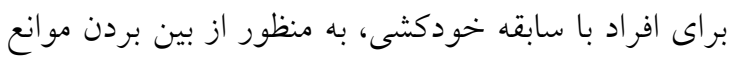

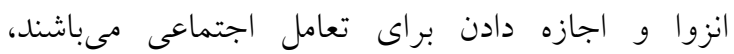
مداخلات با استفاده از اين فرصتها براى تحقيقات آينده ييشنهاد مىشود.

تعارض منافع: هيج گونه تعارض منافع توسط نويسندگان

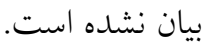

\section{تقدير و تشكر}

اين مقاله بخشى از طرح يزوهشى بايان نامه كارشناسى

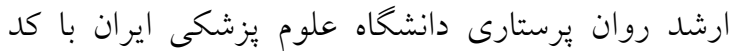
IFro علوم بزشكى ايران كه تصويب طرح و حمايت مالى آن را

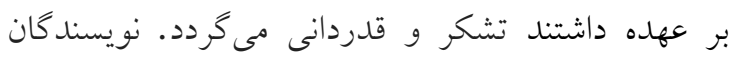
مراتب تقدير و تشكر خود را از واحد توسعه تحقيقات

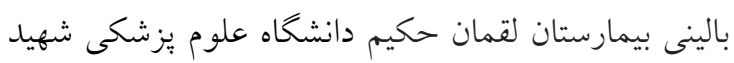

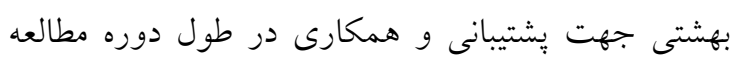

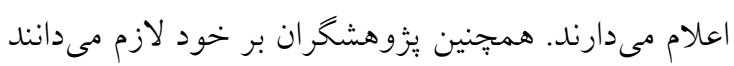
از زحمات و همكارى صميمانه تمام افراد شركت كننده در مطالعه سباسگز ارى و قدردانى نمايند.
هايى كه افراد اقدام كننده به خودكشى معمولاً به آن جا

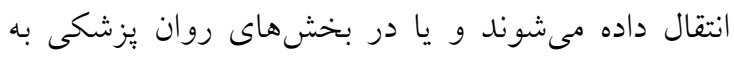

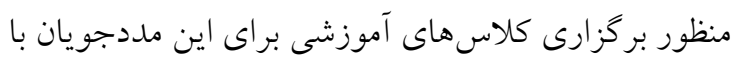

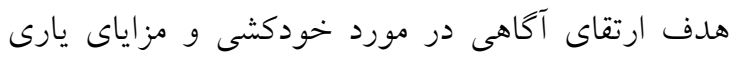

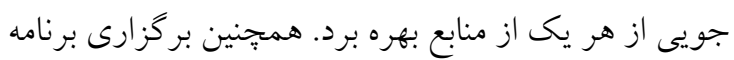
هاى آموزشى در محيطهاى كارى، آموزشى، بالينى و غيره

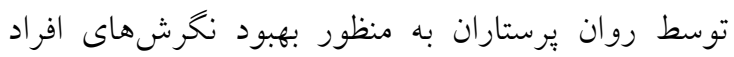
نسبت به صحبت در مورد تنشها و افكار خودكشى و به منظور توانمند نمودن شركت كنند كان به عنوان يارى رسان

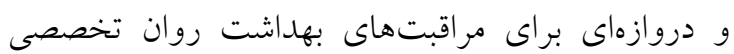
بيشنهاد مى گردد. حمايت مطلوب و مر اقبت بهداشت روان بايد جنبههاى اجتماعى و ساختارى مشكلات افراد از جمله

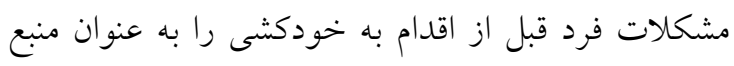

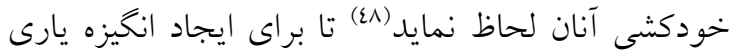
جويى مؤثرتر باشند. بنابر اين براى افراد بايد اين ييام واضح

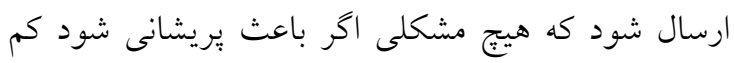

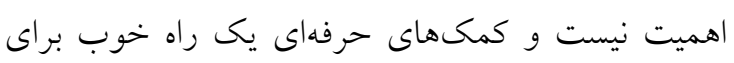

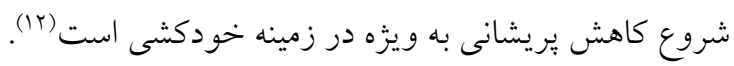

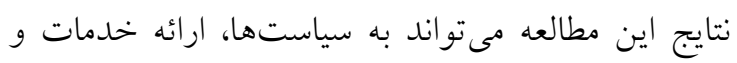
راهبردهاى ارتقاء سلامت روان به منظور حمايت بيشتر از

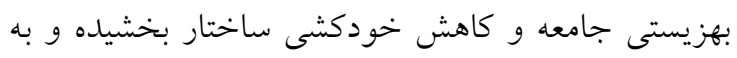

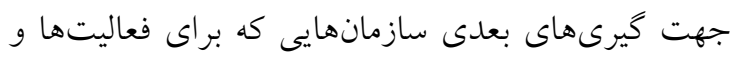

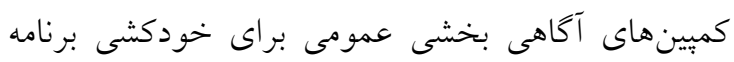

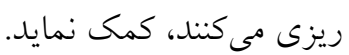
از محدوديتهاى اجرايى اين طرح مى دونوان به اين اشاره

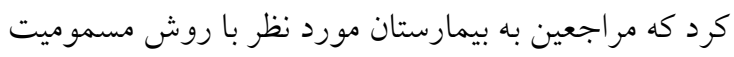

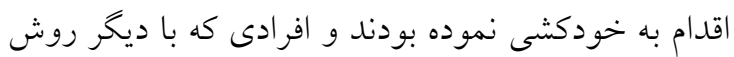
ها اقدام به خودكشى نمودهاند، در مطالعه حضور نداشتند.

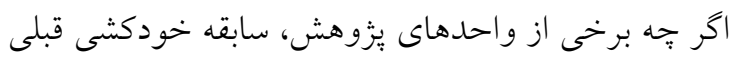

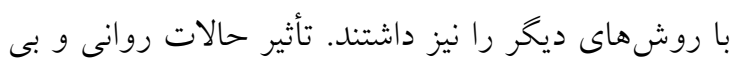

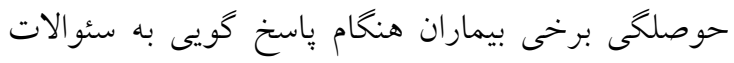

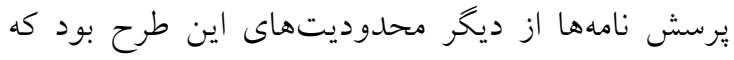




\section{References}

1. Boyd MA. psychiatric nursing(contemporary practice). $6^{\text {th }}$ ed. Illinois: Wolters kluwer; 2018.

2. WHO. Suicide prevention. Geneva: The Organization;2019. Available from: https://www.who.int/health-topics/suicide\#tab=overview. Accessed sep 25 ،2019.

3. Naghavi M. Global, regional, and national burden of suicide mortality 1990 to 2016: systematic analysis for the Global Burden of Disease Study 2016. bmj. 2019;364(194):1-11.

4. Compare GB. Viz Hub. Institute for Health Metrics and Evaluation [website]. Seattle, WA: Institute for Health Metrics and Evaluation, University of Washington. 2019. Available from: https://gbd2016.healthdata.org/gbd-compare/. 2019.

5. IRNA. Access to mental health services reduces suicide. Tehran: News Agency; 2019. Available from: https://www.irna.ir/news/83466055./ Accessed sep 5 ،2019. [Persian]

6. Cleary A. Help-seeking patterns and attitudes to treatment amongst men who attempted suicide. $J$ Ment Health. 2017;26(3):220-4.

7. Shaker SH, Kasnaviyyeh SM, Ghafouri HB, Tavakkoli N, Yasinzadeh M, Masoumi G, Chahardovali M, Amiri H, Attaran H, Koohestani L, Noughan ZE. XML Epidemiological survey of the attempted suicide patients admitted at Hazrat Rasoul Hospital in Tehran 2007-2011. Iranian Journal of Forensic Medicine. 2017;23(1):7-15. [Persian]

8. Frey LM, Hans JD, Cerel J. Suicide disclosure in suicide attempt survivors: Does family reaction moderate or mediate disclosure's effect on depression?. Suicide and Life-Threatening Behavior. 2016;46(1):96-105.

9. Oexle N, Herrmann K, Staiger T, Sheehan L, Rüsch N, Krumm S. Stigma and suicidality among suicide attempt survivors: a qualitative study. Death studies. 2018;43(6):381-8.

10. Scocco P, Castriotta C, Toffol E, Preti A. Stigma of Suicide Attempt (STOSA) scale and Stigma of Suicide and Suicide Survivor (STOSASS) scale: two new assessment tools. Psychiatry Research. 2012;200(2-3):872-8.

11. Kearns M, Muldoon OT, Msetfi RM, Surgenor PW. Understanding help-seeking amongst university students: the role of group identity, stigma, and exposure to suicide and help-seeking. Frontiers in psychology. 2015;6(1462):1-8.

12. Rickwood D, Deane FP, Wilson CJ, Ciarrochi J. Young people's help-seeking for mental health problems. Australian e-journal for the Advancement of Mental health. 2005;4(3):218-51.

13. Reynders A, Kerkhof AJ, Molenberghs G, Van Audenhove C. Attitudes and stigma in relation to help-seeking intentions for psychological problems in low and high suicide rate regions. Soc Psych Psychiat Epidemiol. 2014;49(2):231-9.

14. Chan WI, Batterham P, Christensen H, Galletly C. Suicide literacy, suicide stigma and help-seeking intentions in Australian medical students. Australasian Psychiatry. 2014;22(2):132-9.

15. Yap MB, Reavley NJ, Jorm AF. Associations between stigma and help-seeking intentions and beliefs: Findings from an Australian national survey of young people. Psychiatry Research. 2013;210(3):1154-60.

16. Cryer RE, Calear AL, Batterham PJ, Patel SR. Suicide, mental, and physical health condition stigma in medical students. Death studies. 2020 2;44(4):230-6.

17. Dervic K, Akkaya-Kalayci T, Friedrich MH, Csorba J, Tringer L, Rozsa S, Lenz G. Attitudes toward suicide and help-seeking in Hungarian adolescents [5]. J Am Acad Child Adolescent Psychiatry. 2005;44(7):628-9.

18. Rimkeviciene J, Hawgood J, O'Gorman J, De Leo D. Personal stigma in suicide attempters. Death studies. 2015;39(10):592-9

19. Bidel Z, Nazarzadeh M, Ayubi E, Sayehmiri K. Prevalence of important poisoning methods used in Iranian suicides: a systematic review and meta-analysis. Koomesh. 2013;14(3):257-64. [Persian]

20. Daliri S, Bazyar J, Sayehmiri K, Delpisheh A, Sayehmiri F. Investigation of the Incidence rate of suicide in Iran During Years 2001-2014 A Systematic Review and Meta-analysis study. JOURNAL OF SHAHID SADOUGHI UNIVERSITY OF MEDICAL SCIENCES AND HEALTH SERVICES . 2016;24(9):748-56. [Persian]

21. Kashfi SM, Yazdankhah M, Khani Jeihooni A, Motamedi MJ, Babaei Heydarabadi A, Vejdani M. Study of Important Risk Factors of Suicide Attempts in Patients Admitted to Hospitals Covered by Shiraz University of Medical Sciences. Journal of Sabzevar University of Medical Sciences. 2016;23(4):634-43. [Persian] 
22. Monsef Kasmaie V, Asadi P, Maleki Ziabari SM. A Demographic study of suicide methods in the patients aided by emergency Paramedics Guilan. Journal of Guilan University of Medical Sciences. 2013;22(87):31-7. [Persian]

23. Shokrzadeh M, Hoseinpoor R, Hajimohammadi A, Delaram A, Shayeste Y. Epidemiological survey of suicide attempt by drug poisoning in Gorgan, Iran, 2008 to 2015. Journal of Mazandaran University of Medical Sciences. 2016;26(143):201-10. [Persian]

24. Pattyn E, Verhaeghe M, Sercu C, Bracke P. Medicalizing versus psychologizing mental illness: what are the implications for help seeking and stigma? A general population study. Soc Psych Psychiat Epidemiol. 2013;48(10):1637-45.

25. Pattyn E, Verhaeghe M, Sercu C, Bracke P. Public stigma and self-stigma: Differential association with attitudes toward formal and informal help seeking. Psychiatric Services. 2014;65(2):232-8.

26. Rüsch N, Heekeren K, Theodoridou A, Dvorsky D, Müller M, Paust T, Corrigan PW, Walitza S, Rössler W. Attitudes towards help-seeking and stigma among young people at risk for psychosis. Psychiatry Research. 2013;210(3):1313-5.

27. Calear AL, Batterham PJ, Christensen H. Predictors of help-seeking for suicidal ideation in the community: risks and opportunities for public suicide prevention campaigns. Psychiatry Research. 2014;219(3):525-30.

28. Hollinger JM. Adolescent Attitudes Toward and Perceptions of Suicide, Stigma, and Help-Seeking Behavior. Unpublished PhD.Thesis, Philadelphia College of Osteopathic Medicine. 2016.

29. Ko J. Help-seeking pathway among working-age adults with suicidal ideation: testing the integrated model of suicide help-seeking. Social work in public health. 2018;33(7-8):467-82.

30. Michelmore L, Hindley P. Help-seeking for suicidal thoughts and self-harm in young people: A systematic review. Suicide and Life-Threatening Behavior. 2012;42(5):507-24.

31. Han J, Batterham PJ, Calear AL, Ma J. Seeking professional help for suicidal ideation: A comparison between Chinese and Australian university students. Psychiatry research. 2018;270:807-14.

32. Wilson CJ, Deane FP, Ciarrochi JV, Rickwood D. Measuring help seeking intentions: properties of the general help seeking questionnaire. Revue canadienne de counseling. 2005;39(1):15-28.

33. Olivari C, Guzman-Gonzalez M. Validation of the general help-seeking questionnaire for mental health problems in adolescents. Revista Chilena de Pediatria. 2017;88(3):324-31.

34. Zeinali E. Assessment of relationship between medication adherence with coping strategies and help-seeking among clients with chronic Heart failure. Unpublished master of psychiatric nursing. dissertation, Iran University of Medical Sciences. 2017. [Persian]

35. Wilks CR, Coyle TN, Krek M, Lungu A, Andriani K. Suicide ideation and acceptability toward online help-seeking. Suicide and Life-Threatening Behavior. 2018;48(4):379-85.

36. Frey LM, Hans JD, Cerel J. Perceptions of suicide stigma: How do social networks and treatment providers compare?. Crisis: The Journal of Crisis Intervention and Suicide Prevention. 2016;37(2):95.

37. Han J, Batterham PJ, Calear AL, Wu Y, Xue J, van Spijker BA. Development and pilot evaluation of an online psychoeducational program for suicide prevention among university students: A randomised controlled trial. Internet interventions. 2018;12:111-20.

38. Lueck JA. What's the risk in seeking help for depression? Assessing the nature and pleasantness of outcome perceptions among individuals with depressive symptomatology. Health Educ Behav. 2019;46(3):463-70.

39. Azizpour M, Taghizadeh Z, Mohammadi N, Vedadhir A. Fear of stigma: The lived experiences of Iranian women after suicide attempt. Perspectives in psychiatric care. 2018;54(2):293-9.

40. Barney LJ, Griffiths KM, Jorm AF, Christensen H. Stigma about depression and its impact on helpseeking intentions. Aust New Zealand J Psychiatry. 2006;40(1):51-4.

41. Taylor-Rodgers E, Batterham PJ. Evaluation of an online psychoeducation intervention to promote mental health help seeking attitudes and intentions among young adults: randomised controlled trial. J Affect Disord. 2014;168:65-71.

42. Blais RK, Renshaw KD. Stigma and demographic correlates of help-seeking intentions in returning service members. J Traumatic Stress. 2013;26(1):77-85. 
43. Mahdizadeh M, khosravi Z, editors. A Review of the Stigmatization in the Iranian Community and Muslim World: 2017: Proceedings of The First International Conference on Culture, Psychopathology and Education; 2017 May 3-4 ,Iran; Tehran: Alzahra University; 2017. [Persian]

44. Rickwood D, Thomas K. Conceptual measurement framework for help-seeking for mental health problems. Psychol Res Behavr Manag. 2012;5:173.

45. Czyz EK, Horwitz AG, Eisenberg D, Kramer A, King CA. Self-reported barriers to professional help seeking among college students at elevated risk for suicide. J Am College Health. 2013;61(7):398-406.

46. Tucker JR, Hammer JH, Vogel DL, Bitman RL, Wade NG, Maier EJ. Disentangling self-stigma: Are mental illness and help-seeking self-stigmas different?. J Couns Psychol. 2013;60(4):520.

47. Reynders A, Kerkhof AJ, Molenberghs G, Van Audenhove C. Stigma, attitudes, and help-seeking intentions for psychological problems in relation to regional suicide rates. Suic Life-Threat Behav. 2016;46(1):67-78.

48. Weiss MG, Parkar SR. Facets of clinical stigma after attempted suicide in Mumbai, India. Anthropol Med. 2020;27(2):212-33. 